OPEN ACCESS

Edited by:

Eric Cox,

Ghent University, Belgium

Reviewed by:

Yasuko Tsunetsugu Yokota,

Tokyo University of Technology, Japan

Mark Travis,

University of Manchester,

United Kingdom

*Correspondence:

Diane Bimczok

diane.bimczok@montana.edu

tThese authors have contributed equally to this work

Specialty section

This article was submitted to

Mucosal Immunity,

a section of the journal

Frontiers in Immunology

Received: 16 August 2018 Accepted: 04 December 2018

Published: 21 December 2018

Citation:

Swain S, Roe MM, Sebrell TA,

Sidar B, Dankoff J, VanAusdol R,

Smythies LE, Smith $P D$ and Bimczok D (2018) CD103 ( $\alpha E$ Integrin) Undergoes Endosomal Trafficking in Human Dendritic Cells, but Does Not

Mediate Epithelial Adhesion.

Front. Immunol. 9:2989.

doi: 10.3389/fimmu.2018.02989

\section{CD103 ( $\alpha$ E Integrin) Undergoes Endosomal Trafficking in Human Dendritic Cells, but Does Not Mediate Epithelial Adhesion}

\author{
Steve Swain ${ }^{1 \dagger}$, Mandi M. Roe ${ }^{1 \dagger}$, Thomas A. Sebrell ${ }^{1}$, Barkan Sidar ${ }^{2}$, Jennifer Dankoff ${ }^{1}$, \\ Rachel VanAusdol ${ }^{1}$, Lesley E. Smythies ${ }^{3}$, Phillip D. Smith ${ }^{3}$ and Diane Bimczok ${ }^{1 *}$ \\ ${ }^{1}$ Department of Microbiology and Immunology, Montana State University, Bozeman, MT, United States, ${ }^{2}$ Chemical and \\ Biological Engineering Department, Montana State University, Bozeman, MT, United States, ${ }^{3}$ Division of Gastroenterology \\ and Hepatology, School of Medicine, University of Alabama at Birmingham, Birmingham, AL, United States
}

Dendritic cell (DC) expression of CD103, the $\alpha$ subunit of $\alpha E \beta 7$ integrin, is thought to enable DC interactions with E-cadherin-expressing gastrointestinal epithelia for improved mucosal immunosurveillance. In the stomach, efficient DC surveillance of the epithelial barrier is crucial for the induction of immune responses to $H$. pylori, the causative agent of peptic ulcers and gastric cancer. However, gastric DCs express only low levels of surface CD103, as we previously showed. We here tested the hypothesis that intracellular pools of CD103 in human gastric DCs can be redistributed to the cell surface for engagement of epithelial cell-expressed E-cadherin to promote DC-epithelial cell adhesion. In support of our hypothesis, immunofluorescence analysis of tissue sections showed that CD103 ${ }^{+}$ gastric DCs were preferentially localized within the gastric epithelial layer. Flow cytometry and imaging cytometry revealed that human gastric DCs expressed intracellular CD103, corroborating our previous findings in monocyte-derived DCs (MoDCs). Using confocal microscopy, we show that CD103 was present in endosomal compartments, where CD103 partially co-localized with clathrin, early endosome antigen-1 and Rab11, suggesting that CD103 undergoes endosomal trafficking similar to $\beta 1$ integrins. Dynamic expression of CD103 on human MoDCs was confirmed by internalization assay. To analyze whether DC-expressed CD103 promotes adhesion to E-cadherin, we performed adhesion and spreading assays on E-cadherin-coated glass slides. In MoDCs generated in the presence of retinoic acid, which express increased CD103, intracellular CD103 significantly redistributed toward the E-cadherin-coated glass surface. However, DCs spreading and adhesion did not differ between E-cadherin-coated slides and slides coated with serum alone. In adhesion assays using E-cadherin-positive HT-29 cells, DC binding was significantly improved by addition of $\mathrm{Mn}^{2+}$ and decreased in the presence of EGTA, consistent with the dependence of integrin-based interactions on divalent cations. However, retinoic acid failed to increase DC adhesion, and a CD103 neutralizing 
antibody was unable to inhibit DC binding to the E-cadherin positive cells. In contrast, a blocking antibody to DC-expressed E-cadherin significantly reduced DC binding to the epithelium. Overall, these data indicate that CD103 engages in DC-epithelial cell interactions upon contact with epithelial E-cadherin, but is not a major driver of DC adhesion to gastrointestinal epithelia.

Keywords: gastrointestinal epithelium, integrin alpha E, antigen-presenting cell, cell adhesion, endosome

\section{INTRODUCTION}

Dendritic cells (DCs) frequently interact with the epithelial layer of the gastric mucosa, as shown in previous studies (1-3). As professional antigen-presenting cells, DCs control the immune response to Helicobacter pylori (H. pylori) (4), a bacterial pathogen that causes chronic gastritis, peptic ulcer disease, and gastric cancer (5-7). Specifically, the type of $\mathrm{T}$ cell response induced by the DCs largely determines whether H. pylori infection causes only mild inflammation or leads to severe inflammatory pathologies including ulcers or cancer (810). For those DCs that are located immediately beneath or within the gastric epithelium, their spatial interactions with the epithelial cells have important functional implications for the immune response to $H$. pylori. First, DCs that reside within the epithelial layer or extend transepithelial dendrites have direct access to the gastric lumen for $H$. pylori antigen sampling (1$3,11)$. Second, positioning of gastric DCs immediately below the epithelium increases the probability for pathogen capture upon epithelial barrier breach, and third, the close proximity of DCs to epithelial cells likely enhances the paracrine effects of epithelial-derived mediators that regulate DC function (1214). In spite of the importance of DC-epithelial interactions for gastrointestinal immune responses, the molecular mechanisms of these interactions are not well-defined.

Binding of DC-expressed CD103 ( $\alpha$ Eß7 integrin) to epithelial E-cadherin was proposed as a potential mechanism for DC adhesion to epithelial cells (15-17). CD103, the $\alpha$ subunit of $\alpha E ß 7$ integrin, is widely recognized as an important DC subset and lineage marker in humans and mice (18-20). Specifically, CD103 identifies a DC subset termed conventional DC1 that is able to cross-present exogenous antigens to CD8 T cells and that induces mucosal tolerance to commensals and dietary antigens $(18,21)$. The functional role of CD103 has been extensively studied in transfected cells lines, where the A-domain of the $\alpha \mathrm{E}$ (CD103) integrin subunit was shown to interact with the top surface of Ecadherin domain 1, and in intestinal intraepithelial lymphocytes (IELs), where CD103 anchors the IELs within the epithelial layer (22-24). Inspite of its frequent use as a DC marker, the function of CD103 in primary human DCs has received little investigative attention. Therefore, the goal of our study was to determine whether CD103 enables DCs in the human stomach to interact with the epithelium through E-cadherin engagement.

Notably, previous studies from our laboratory and others have shown that surface CD103 expression of gastric DCs is low compared to CD103 expression on DCs in other tissue compartments, such as the small intestine (14, 25-27). This low surface CD103 expression was unexpected, since gastric DCs have a tolerogenic capacity similar to that of human intestinal DCs $(14,28)$ and also are efficient producers of retinoic acid (RA), properties generally associated with intestinal $\mathrm{CD}_{103^{+}}{ }^{-} \mathrm{DC}$ subsets $(14,29,30)$. However, we also showed that human monocyte-derived DCs express considerable amounts of CD103 in intracellular compartments (26). Other integrins including $\alpha 5 \beta 1, \alpha 6 \beta 4$, and $\alpha \mathrm{M} \beta 2$ are expressed in endosomal compartments and recirculate through the membrane to enable dynamic and tightly regulated interactions with their respective ligands (31-33). Therefore, we hypothesized that intracellular pools of $\alpha \mathrm{E}$ integrin/CD103 present in human gastric DCs can be redistributed to the cell surface for engagement of epithelial cellexpressed E-cadherin in the stomach to promote DC-epithelial cell adhesion. Interestingly, our experiments revealed that CD103 undergoes endosomal trafficking in human DCs and is engaged upon DC contact with epithelial E-cadherin, but is not the major adhesion factor that mediates epithelial cell binding.

\section{MATERIALS AND METHODS}

\section{Human Blood and Tissue Samples}

Heparinized blood samples were obtained with local IRB approval from healthy adult volunteers in Birmingham, AL (IRB\# X120806005), or Bozeman, MT (IRB \#DB082817 and \#DB092614). Gastric tissue specimens were obtained with Institutional Review Board (IRB) approval and informed consent from non- $H$. pylori-infected adult subjects undergoing elective gastric bypass surgery or sleeve gastrectomy for treatment of obesity at the University of Alabama at Birmingham (IRB\# F120815005) or were provided as exempt specimens by the National Disease Research Interchange (Philadelphia, PA; IRB\# DB062615-EX).

\section{Antibodies}

The following mouse anti-human monoclonal antibodies were used for flow cytometry, imaging cytometry and confocal analysis of MoDCs: HLA-DR (clone L243), CD11c (B-ly6), CD103/ $\alpha$ E (B-Ly7,) CD3 (HIT3a), CD19 (SJ25C1), CD45 (2D1), CD56 (MY31), E-cadherin (67A4), CD49d (9F10) purchased from eBioscience, Biolegend, or Tonbo, all San Diego, CA. Endosomal compartments were labeled with rabbit anti-human clathrin (D3C6, Cell Signaling, Danvers, MA), rabbit antihuman EEA-1 (polyclonal), mouse anti-human Rab7a (Rab7117), and rabbit anti-human Rab11 (polyclonal), all from Abcam, Cambridge, MA. The following monoclonal antibodies were 
used for staining of paraffin-embedded tissue sections: antihuman HLA-DR (LN-3) and anti-human CD103 [EPR4166(2)], both Abcam, Cambridge, MA. The following antibodies were used in neutralization assays: anti-human CD103 (2G5) (Beckman Coulter, France) and anti-human E-cadherin (SHE787) (Thermo Fisher Scientific, Waltham, MA). Appropriate isotype-matched control antibodies were used in all experiments.

\section{Dendritic Cells}

To obtain human gastric DCs, mucosal tissue was subjected to three rounds of EDTA treatment and then digested with collagenase solution to obtain lamina propria mononuclear cells, as described previously $(14,26)$. Gastric DCs were then enriched using MACS sorting for $\mathrm{HLA}_{-} \mathrm{DR}^{+}$cells (Miltenyi Biotec, Auburn, CA).

To generate monocyte-derived DCs (MoDCs), PBMCs were isolated using Ficoll density gradient centrifugation, and MoDCs were differentiated from MACS-isolated CD14 ${ }^{+}$blood monocytes by culturing $2 \times 10^{6}$ monocytes per well in 24well plates in complete medium (DMEM, 10\% heat-inactivated human $\mathrm{AB}$ serum and antibiotics) or serum-free medium (XVivo 10, with HEPES and L-Glutamine) supplemented with recombinant human GM-CSF $(25 \mathrm{ng} / \mathrm{mL})$, and IL-4 $(17 \mathrm{ng} / \mathrm{mL})$, both from R\&D Systems, Minneapolis, $M N(26,28)$. To enhance DC CD103 expression, $100 \mathrm{nM}$ retinoic acid (RA, Sigma, St. Louis, MO) was added to some MoDC cultures, as described previously (26). Cytokines and RA were replenished after 3 days, and after 5-6 days, non-adherent cells were harvested as MoDCs by vigorous pipetting.

\section{Immunofluorescent Labeling of Tissues and Cells for Microscopy}

We used $4 \mu \mathrm{m}$ paraffin-embedded sections to analyze CD103 expression by human gastric DCs in situ. Sections were deparaffinized and then incubated in a vegetable steamer for $30 \mathrm{~min}$ in pre-heated Unmasking Solution (Vector Laboratories, Burlingame, CA) for antigen retrieval. Sections were then blocked in normal goat serum and incubated in the presence of primary antibodies overnight. Species specific secondary antibodies labeled with Alexa 488 or Alexa 555 (SouthernBiotech, Birmingham, AL) were added for $30 \mathrm{~min}$. Finally, nuclei were stained with DAPI, and sections were mounted in Fluoroshield (Sigma-Aldrich) and sealed with nail varnish. For microscopic analysis of MoDCs, cells were stained either directly on glassbottom plates or chamber slides (CD103 distribution and spreading assays) or were stained in suspension and then spotted onto glass slides (endosomal markers). For intracellular labeling, DCs were permeabilized with Cytofix/Cytoperm solution (Becton Dickinson) for $20 \mathrm{~min}$ at $4^{\circ} \mathrm{C}$, washed with PermWash buffer (Becton Dickinson) and then were incubated with antibodies for $30 \mathrm{~min}$ at $4^{\circ} \mathrm{C}$. Nuclei were labeled with DRAQ5 or DAPI.

\section{Microscopy and Image Analysis}

Immunofluorescence analysis of slides was performed on an Olympus BX60 upright fluorescence microscope equipped with a DS-Ri1 digital camera and with NIS Elements software
(Nikon, Melville, NY) or on an EVOS FL Cell Imaging system (Thermo Fisher Scientific). Confocal microscopy images were acquired using a Zeiss LSM 510 META system, with a $63 \times$ objective and a step size of $0.5 \mu \mathrm{m}$, or an inverted Leica SP5 Confocal Scanning Laser Microscope (Leica, Wetzlar, Germany) with a $20 \times$ objective or a $63 \times$ water immersion objective with Immersol (W 2010, Zeiss, Oberkochen, Germany). Digital image analysis was performed using ImageJ $1.48 \mathrm{v}$ software. The distribution of $\mathrm{CD} 103^{+} \mathrm{DCs}$ in relation to the epithelium in gastric tissue sections was determined by manual counting on digital images, using NIS Elements software. Three-dimensional co-localization of red (endosomal markers) and green (CD103) voxels in confocal stacks was determined using the JaCOP plugin to calculate Mander's co-localization coefficient (34). Part of this procedure involved screening 16 algorithms for optimal exclusion of background staining; the Bernsen method of autothresholding was chosen and applied objectively to all images (35). In tissue sections, regions of interest were set to exclude surface and glandular epithelial cells.

\section{FACS Analysis}

For flow cytometry, cells were labeled with pre-determined optimum concentrations of antibodies at $4^{\circ} \mathrm{C}$ for $15 \mathrm{~min}$, followed by washing in FACS Stain Buffer (BD Biosciences). For intracellular staining, cells were fixed and permeabilized with Cytofix/Cytoperm (BD Bioscience), and antibodies we added in the presence of BD PermWash buffer. Dead cells were labeled with LIVE/DEAD ${ }^{\circledR}$ yellow dye (Life Technologies, Carlsbad, CA). A BD LSR or LSRII was used for flow cytometry; and data were analyzed using FlowJo V10 software (Treestar, Ashland, OR). Gastric DCs were gated as live CD45 ${ }^{\text {pos }} /$ lineage $e^{\text {neg }} / \mathrm{HLA}$ $\mathrm{DR}^{\text {high }}$ cells. The lineage cocktail contained antibodies to CD3, CD19, and CD56.

\section{Imaging Cytometry}

Imaging cytometry was performed using an ImageStreamX Mark II (Amnis Corp., Seattle, WA). Cells were prepared as described for FACS analysis, with 7-AAD or DAPI used to label nuclei in fixed cells. Data were analyzed with IDEAS software v6.1 (Amnis Corp.). The following channels were recorded: Ch 1-brightfield, Ch 2-CD103 FITC, channel 3-CD11c PE, and channel 5-7-AAD or channel 7-DAPI. DCs were gated as focused cells based on Gradient RMS Ch 1, single cells based on Aspect Ratio and Area Ch1, and Intensity of CD11c PE in Ch 3.

\section{Internalization Assay}

Relative rates of internalization of CD103 were determined in MoDCs using a variation of the method from Chen et al. (36). Briefly, aliquots of MoDCs generated in the presence of retinoic acid $(100 \mathrm{nM})$ were chilled to $4^{\circ} \mathrm{C}$, then incubated with FITC labeled mouse anti-human CD103 for $30 \mathrm{~min}$. Unbound antibody was then removed by washing in ice cold media. Time zero samples were left on ice, and internalization was initiated in the remaining samples by resuspending the samples in $37^{\circ} \mathrm{C}$ media and incubating them at that temperature for the indicated times. At each time point, samples were quickly washed in ice cold FACS buffer and left on ice to inhibit further 
internalization. After washing, cells were incubated for $30 \mathrm{~min}$ with anti-mouse IgG eFluor660 to label remaining cell surface anti-CD103 antibodies. Cells were then washed again in cold FACS buffer and analyzed with a BD LSR flow cytometer. Mean fluorescent intensities were normalized to the highest value of that fluorophore in each experiment.

\section{Adhesion and Spreading Assays}

For adhesion and spreading assays with recombinant E-cadherin, glass bottom 24-well or 96-well plates were coated with goat antihuman IgG at $5 \mu \mathrm{g} / \mathrm{mL}$ and incubated overnight at $4^{\circ} \mathrm{C}$. Nonadherent IgG was washed off with $\mathrm{PBS}+\mathrm{Ca}^{2+}$, and Fc-tagged recombinant human E-cadherin (Acro Biosystems, Newark, DE) at $2 \mu \mathrm{g} / \mathrm{mL}$ or an equal volume human serum was added to wells and incubated at room temperature for $1 \mathrm{~h}$. Alternatively, wells were coated directly with $0.2 \mu \mathrm{g} / \mathrm{mL}$ recombinant human Ecadherin (R\&D systems, Minneapolis, MN) for $1 \mathrm{~h}$. After coating, wells were washed, blocked with human serum, and washed again. MoDCs were incubated for $30 \mathrm{~min}$ with an anti-human CD103 neutralizing antibody $(20 \mu \mathrm{g} / \mathrm{mL})$, an appropriate isotype control antibody or were left untreated and then were added to the plates at $5 \times 10^{5} / \mathrm{mL}$. After incubation for $40 \mathrm{~min}$ at $37^{\circ} \mathrm{C}$, non-adherent cells were gently washed off and cells were fixed with Cytofix/Cytoperm (BD biosciences, San Jose, CA). MoDCs were blocked with $10 \%$ goat serum and stained with HLA-DR FITC, a secondary IgG2a FITC to enhance signal, and DAPI to label cell nuclei. Wells were then imaged on an EVOS FL Cell imaging system and analyzed using ImageJ.

To quantify DC adhesion to gastrointestinal epithelial cells, HT-29 cells were cultured on 48 well plates for 3 days at a starting concentration of $3 \times 10^{5}$ per well to obtain a $100 \%$ confluency for co-culture. MoDCs generated in medium alone or in the presence of RA were harvested and pre-treated with DC culture medium containing one of the following for $30 \mathrm{~min}$ at $37^{\circ} \mathrm{C}: 2 \mathrm{mM} \mathrm{Mn}^{2+}$; $1 \mathrm{mM}$ EGTA; $2 \mathrm{mM} \mathrm{Mn}^{2+}$ and $1 \mathrm{mM}$ EGTA; anti-human CD103 $(2-20 \mu \mathrm{g} / \mathrm{mL})$; or anti-human E-cadherin $(5 \mu \mathrm{g} / \mathrm{mL})$. MoDCs were next plated with the HT-29 monolayers at $2 \times 10^{5}$ cells per well and incubated for $2 \mathrm{~h}$ at $37^{\circ} \mathrm{C}$, with antibodies or other additives remaining in the culture media. Following incubation, non-adherent cells were gently washed off with media, and adherent MoDCs and HT-29 cells were harvested using $0.25 \%$ trypsin/1 mM EDTA (Millipore, Darmstadt, Germany). Cells were then stained with HLA-DR FITC antibody, counting beads were added, and recovered MoDCs were quantified by flow cytometry. Experiments with $<5 \%$ DC adhesion were excluded from the analyses, because it was difficult to interpret minor changes in adhesion when overall adhesion levels were extremely low. Experiments with low overall adhesion correlated neither with low DC CD103 or E-cadherin expression levels nor with a specific passage number or reduced E-cadherin expression of the HT-29 cells.

To quantify CD103 expression following MoDC HT-29 coculture, a subset of MoDCs were incubated without HT-29 cells and subjected to the same $0.25 \%$ trypsin/1 mM EDTA treatment. MoDCs incubated alone and those co-cultured with HT-29 cells were then stained for CD103 expression and analyzed by flow cytometry.

\section{Statistical Analysis}

Data were analyzed using GraphPad Prism 6.05. Results are presented as mean \pm SEM. Differences between values were analyzed for statistical significance by the two-tailed Student's t-test or one- or two-way ANOVA with appropriate post-hoc analysis as indicated. Differences were considered significant at $P<0.05$.

\section{RESULTS}

\section{Gastric Intraepithelial DCs Contain a Significant CD103-Expressing DC Subset}

Flow cytometric analyses of gastric DCs have shown that $\mathrm{CD}_{103^{+}}{ }^{\mathrm{DC}}$ are rare in both human and murine stomach (14, 25-27). Here, we used immunofluorescence analysis of human gastric tissue sections to analyze CD103 expression by gastric mononuclear phagocytes in more detail. Mucosal DCs, and possibly some macrophages, were identified based on high expression of HLA-DR in conjunction with an irregular cell morphology. Notably, our previous studies showed that gastric HLA-DR ${ }^{\text {high }}$ cells are $\mathrm{CD} 45^{+}$leukocytes that express the DC-specific transcription factor $\mathrm{zDC}$, but not the intestinal macrophage marker CD13 and that do not include B cells, T cells, mast cells, or NK cells $(2,14)$. Our immunofluorescence analyses confirmed that CD103 expression by HLA-DR ${ }^{\text {high }}$ cells in the gastric mucosa relatively rare (Figure 1a). Likewise, the majority of $\mathrm{CD}_{103}{ }^{+}$cells, likely $\mathrm{T}$ lymphocytes, were negative for HLA-DR expression (Figure 1a). However, individual CD103 ${ }^{+}$ HLA-DR $^{+}$DCs were detected in close association with the gastric glandular epithelium, either at intraepithelial sites, or directly below the epithelium (Figures $\mathbf{1 b}, \mathbf{c}$ ). We next performed a quantitative analysis of the distribution of $\mathrm{CD}_{103^{-}}$and $\mathrm{CD} 103^{+}$ DC subsets in relationship to the gastric epithelium by counting DCs at intraepithelial, subepithelial (with epithelial contact), and lamina propria sites (no epithelial contact) (Figures 1d,e). Although intraepithelial HLA-DR ${ }^{+}$DCs represented $<2 \%$ of all gastric mucosal DCs, a proportion $(P \leq 0.05)$ of these cells expressed CD103. Specifically, $46.1 \%$ of intraepithelial gastric HLA-DR ${ }^{+}$cells were positive for CD103 compared to only 10.7 and $6.9 \%$ of $\mathrm{CD} 103^{+}$DCs at subepithelial and lamina propria sites, respectively (Figure 1e). These observations suggest that, in spite of an overall low expression of CD103 by human gastric DCs, CD103 might still contribute to DC interactions with the gastric epithelium in those DCs that are integrated into the epithelial cell layer.

\section{Intracellular Expression of CD103 $(\alpha \mathrm{E}$ Integrin) in Human Monocyte-Derived and Gastric DCs}

Human monocyte-derived DCs (MoDCs) contain intracellular as well as surface-expressed CD103 (26). Having shown that gastric DCs express low levels of surface CD103 overall (14, 26), but that surface CD103 expression is more frequent on gastric intraepithelial DCs (Figures 1b,e), we hypothesized that intracellular CD103 pools may be recruited to the cell membrane to mediate binding to epithelial E-cadherin. Therefore, we next 

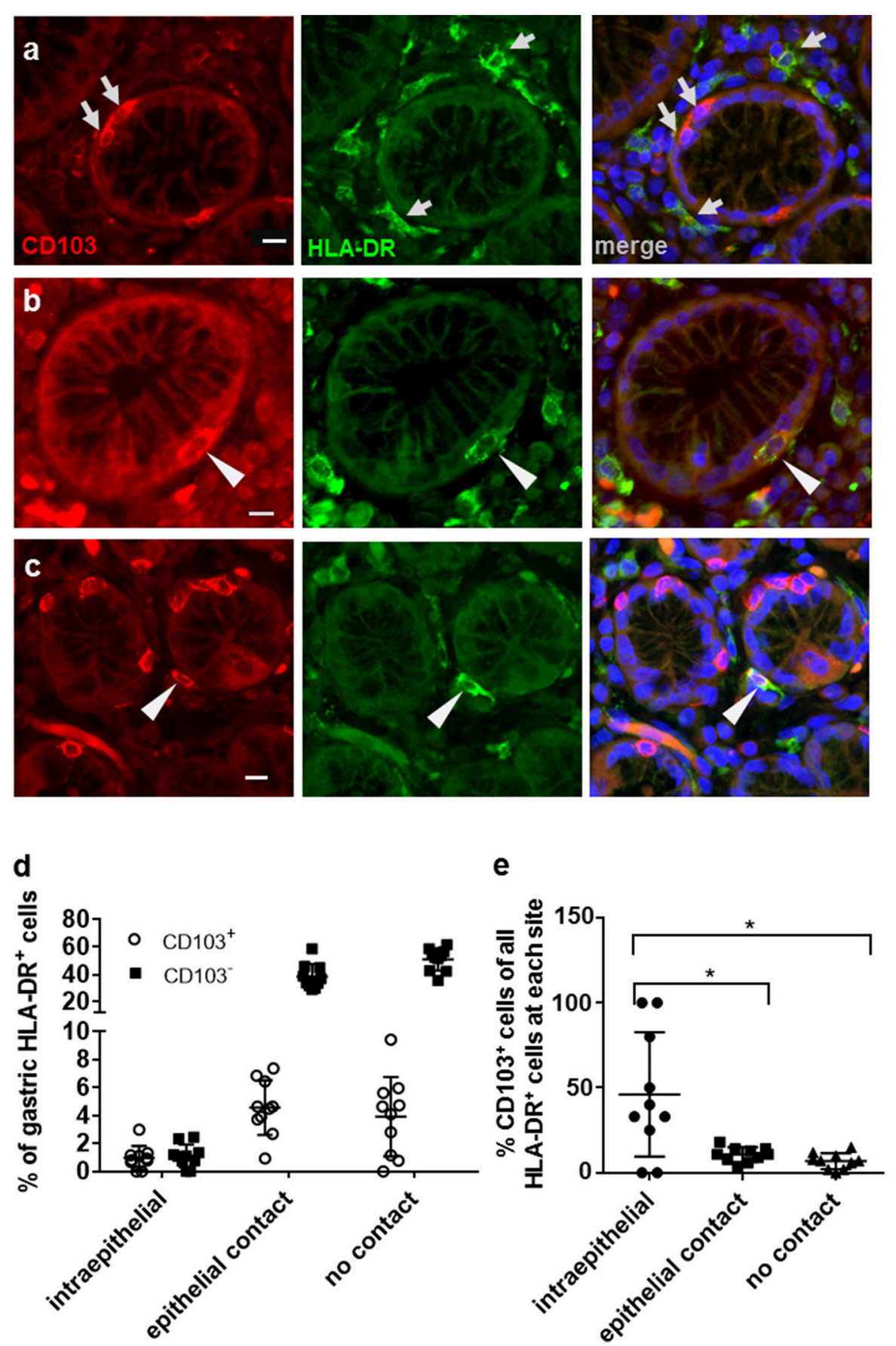

FIGURE 1 | Distribution of CD103+ DCs in human gastric mucosa. Paraffin-embedded tissue sections from the gastric mucosa of non- $H$. pylori-infected human subjects were immunofluorescently labeled for HLA-DR (Alexa 488, green) and CD103 (Alexa 555, red). Nuclei were stained with DAPI. (a) High magnification single color and merged images of gastric mucosa with multiple cells positive for either CD103 or HLA-DR (arrows). (b) Occasional intraepithelial HLA-DR ${ }^{+}$DCs and (c) subepithelial DCs with epithelial contact show staining for CD103. Arrowheads point out HLA-DR ${ }^{+}$DCs that co-express CD103. Bar $=20 \mu m$. (d,e) Quantitative analysis of HLA-DR ${ }^{+}$DCs with and without CD103 expression at intraepithelial, subepithelial (with epithelial contact), and lamina propria sites (no epithelial contact). Tissue sections from 10 human subjects were analyzed. ${ }^{\star} P \leq 0.05$, ANOVA with Tukey's post-hoc test.

analyzed whether primary human gastric DCs also express intracellular CD103. As shown in Figures 2A,C, significant levels of CD103 were detected in both gastric DCs and
MoDCs when cells were permeabilized prior to immunolabeling, consistent with intracellular expression. In addition, intracellular CD103 expression was confirmed by imaging flow cytometry 
(Figures 2D,E). In contrast, we did not observe significant intracellular expression of $\alpha 4$ integrin, in spite of high surface expression (Figure 2B).

Using confocal microscopy, we detected CD103 in vesicular inclusions with a typical endosomal morphology in immature MoDCs with and without concurrent surface CD103 expression (Figure 3A). A similar vesicular staining pattern for CD103 was also seen in DCs isolated from human gastric lamina propria (Figure 3B). Thus, CD103 expression in endosomal compartments appears to be a common feature of human DCs.

\section{CD103 Partially Co-localizes With Clathrin and Early, Recycling, and Late Endosomal Markers}

Previous studies have shown that integrins may undergo endosomal trafficking to allow dynamic interactions with their ligands and facilitate cell migration (32, 37, 38). To characterize the endosomal expression of CD103 in human DCs in more detail, we analyzed co-localization of CD103 with markers for endocytic uptake (clathrin), early endosomes (early endosomal antigen-1, EEA-1), recycling endosomes (Rab11), and late endosomes (Rab7a) in MoDCs (Figure 4). In untreated MoDCs, $23.2 \pm 1.2 \%$ of CD103 was co-localized with clathrin, corresponding to a Manders' co-localization coefficient of 0.232 . Lower coefficients were detected for CD103 co-localization with Rab11 (16.7 $\pm 1.6 \%)$ and the late endosomal marker Rab7a $(16.2 \pm 1.2 \%)$, which targets endosomal cargo for lysosomal degradation (39). Only $6.6 \pm 0.7 \%$ of CD103 co-localized with the early endosomal marker EEA-1. In control slides without primary antibodies, a co-localization co-efficient of $0.71 \pm 0.69 \%$ was measured (data not shown). Interestingly, MoDCs treated with retinoic acid (RA) showed increased co-localization with clathrin $(29.6 \pm 1.3 \% ; P \leq 0.01)$, but lower co-localization with Rab11
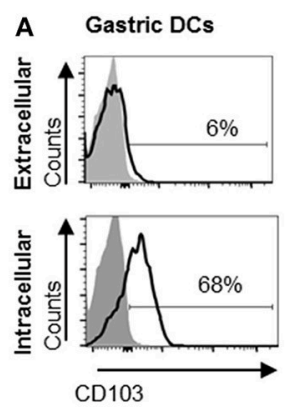

D
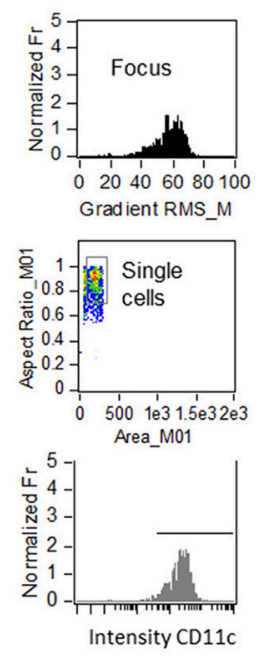
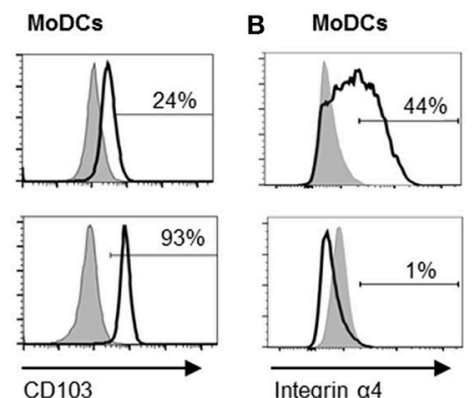

E

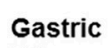
DCs

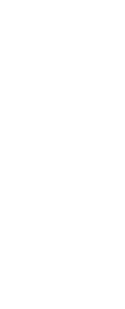

MoDCs
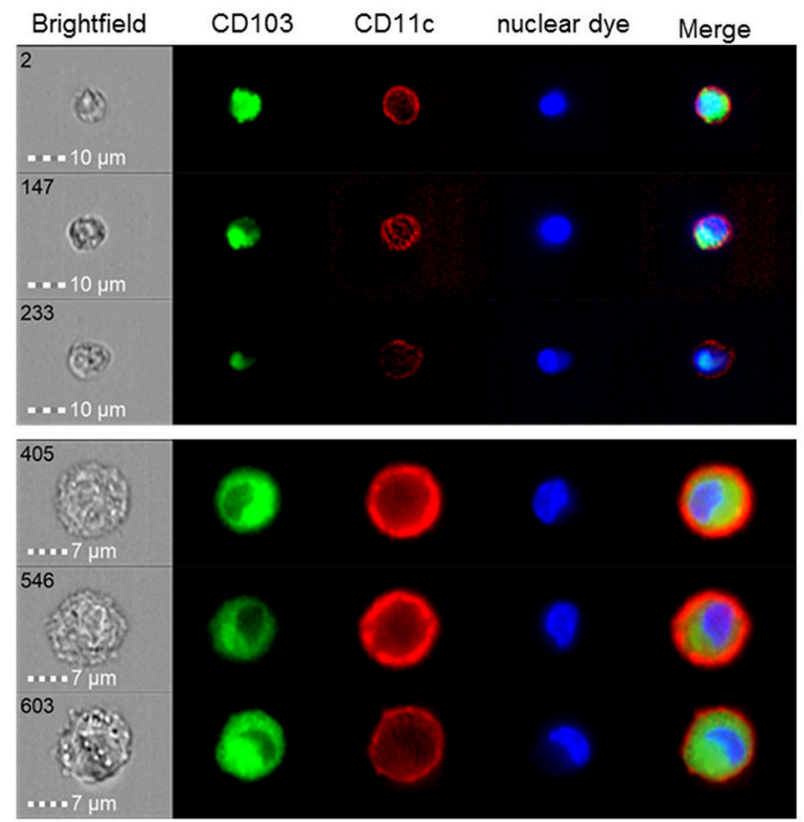

C
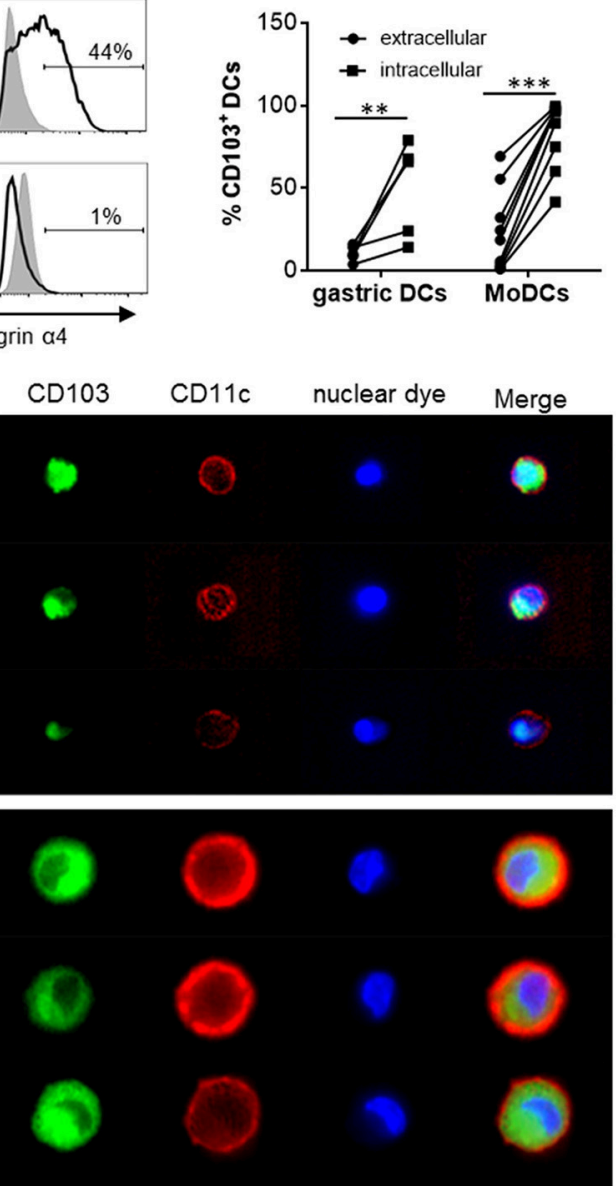

FIGURE 2 | Human gastric and MoDCs contain intracellular CD103 pools. Human gastric DCs gated as live/HLA-DR high $/ C D 45^{\text {pos } / \text { lineage }}{ }^{\text {neg }}$ cells or MoDCs were labeled with (A) an anti-CD103 antibody or (B) an anti- $\alpha 4$ integrin antibody using extracellular or intracellular staining protocols. (A,B) representative histograms and (C) individual values from 4 (gastric DCs) or 9 (MoDCs) independent experiments. ${ }^{\star \star} P \leq 0.01,{ }^{\star \star \star} P \leq 0.001$, ANOVA with Tukey's post-hoc test. (D) Gating strategy for ImageStream imaging cytometry to select for focused, single cells with high CD11c expression. (E) Representative images from three independent imaging cytometry experiments show intracellular CD103 in CD11 $\mathrm{c}^{+}$gastric DCs and MoDCs, 40× objective. BF, bright field; nuclear dye, 7-AAD. 


\section{A MoDCs}
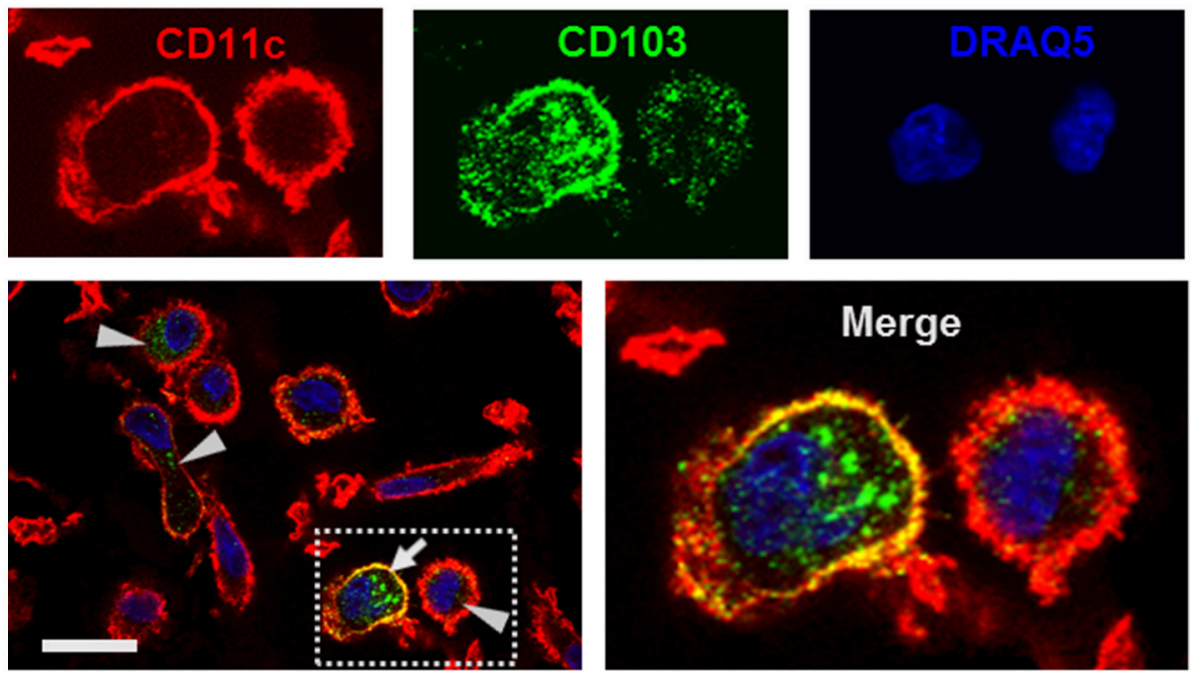

B Gastric DC
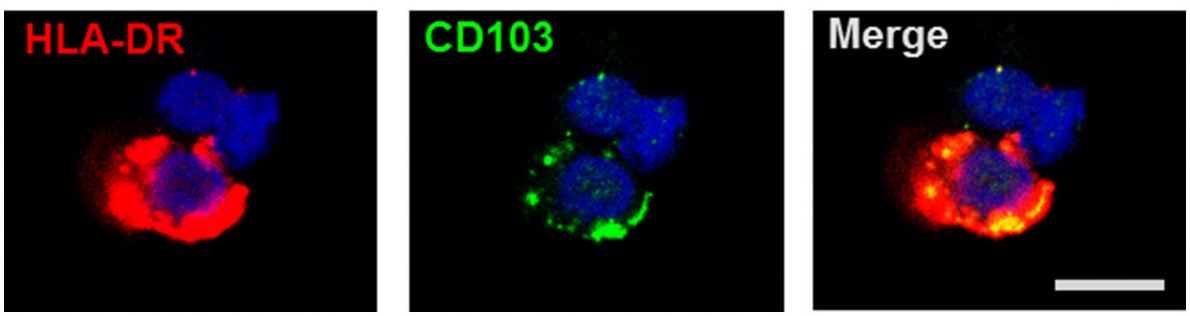

FIGURE 3 | Confocal microscopy analysis shows endosomal expression pattern of CD103 in human monocyte-derived and gastric DCs. (A) Confocal images of human MoDCs that were permeabilized and labeled with antibodies to CD103 (Alexa488) and CD11c (Alexa555) Nuclei were labeled with DRAQ5. Arrowheads point to intracellular CD103+ vesicles in DCs without surface CD103 expression, arrow indicates a DC with both surface and intracellular CD103 expression.

Representative images from one of three similar experiments are shown. Bar: $20 \mu \mathrm{m}$. (B) Gastric lamina propria cells were permeabilized and labeled with antibodies to CD103 (Alexa488) and HLA-DR (Alexa555). Image shows a gastric HLA-DR ${ }^{+}$DC. Bar: $10 \mu \mathrm{m}$.

(12.6 $\pm 1.1 \% ; P \leq 0.05)$. The partial co-localization of CD103 with endosomal markers suggests that CD103 undergoes some endosomal trafficking in human DCs.

\section{CD103 in Human MoDCs Undergoes Continuous Trafficking Through the Cell Membrane}

To functionally analyze whether DC CD103 undergoes endosomal recycling, we performed an internalization assay, as previously described by Chen et al. (36). RA-treated MoDCs were used to achieve a high initial expression of CD103 on the DCs. DCs were then incubated for up to $40 \mathrm{~min}$ at $37^{\circ} \mathrm{C}$ and were kept on ice at all other times to inhibit endosomal trafficking until all cells were collected, with the 0 min sample incubated on ice for the entire $40 \mathrm{~min}$ of the assay. As shown in Figure 5, the level of CD103 on the cell surface as detected with the secondary reagent decreased significantly with prolonged incubation at $37^{\circ} \mathrm{C}(P \leq 0.01)$, whereas total $\mathrm{CD} 103$ expression detected with the primary antibody remained constant. These observations are consistent with internalization of surface expressed CD103 and indicate that CD103 undergoes endosomal recycling, as previously shown for $\alpha 5 \beta 1$ and $\alpha 2 \beta 1$ integrins $(36,37)$. Thus, CD103 may be involved in dynamic binding of DCs to the epithelial layer in spite of low surface expression.

\section{Intracellular CD103 Engages in E-cadherin Binding, but Does Not Mediate DC Adhesion to Epithelial Cells}

Having shown that human DCs contain dynamic pools of intracellular CD103, we next asked whether intracellular CD103 may be recruited to the DC surface for E-cadherin binding. RAtreated or untreated DCs were incubated on glass-bottom plates coated with recombinant E-cadherin (Supplemental Figure 1). The RA-treated DCs expressed increased levels of surface CD103 (Supplemental Figure 2). We hypothesized that engagement of E-cadherin by DC CD103 would lead to an accumulation of CD103 staining close to the E-cadherin-coated glass surface (Figure 6A). Our analysis of CD103 distribution across the 


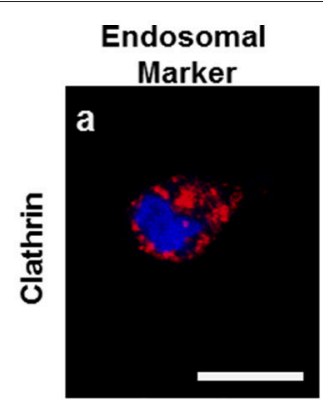

CD103
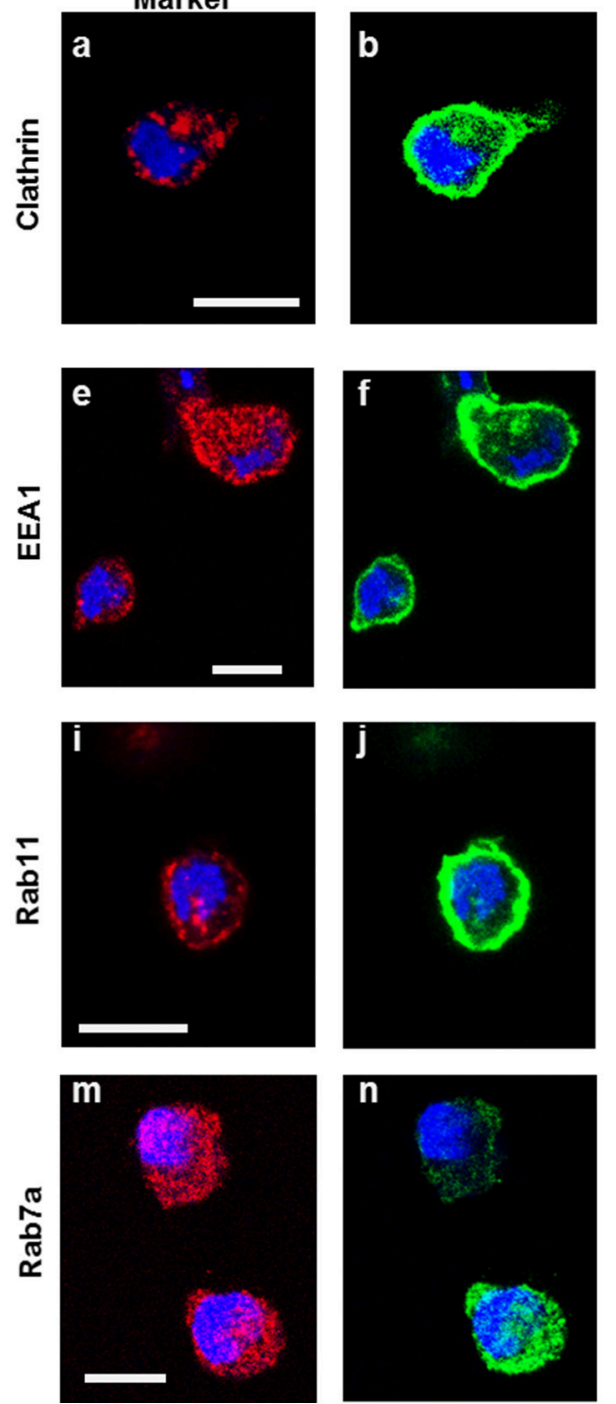
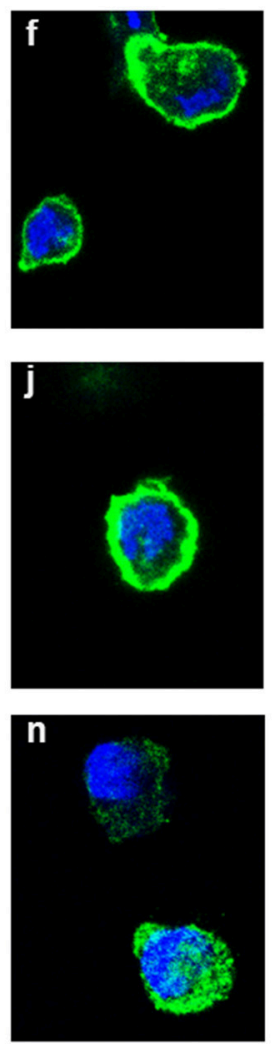

Merged

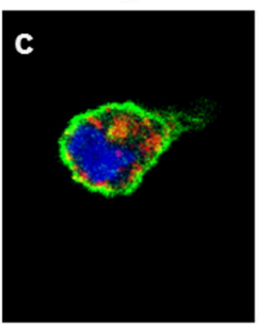

d
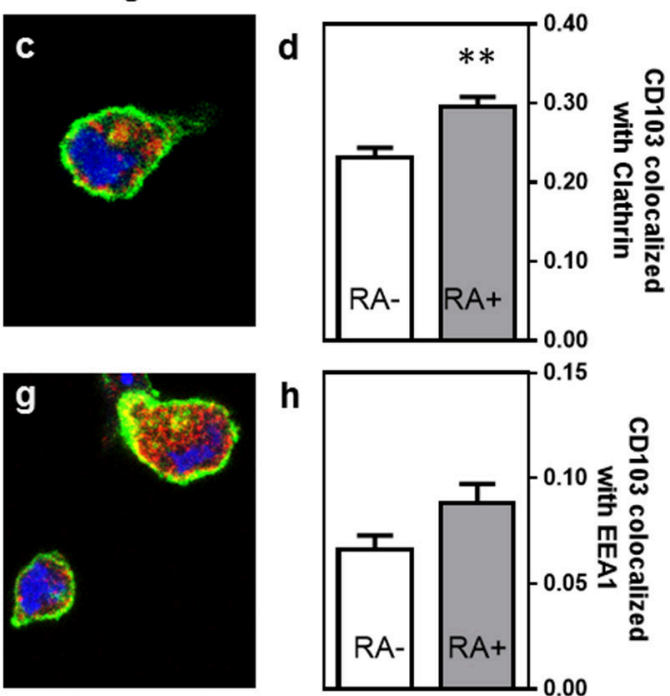

h
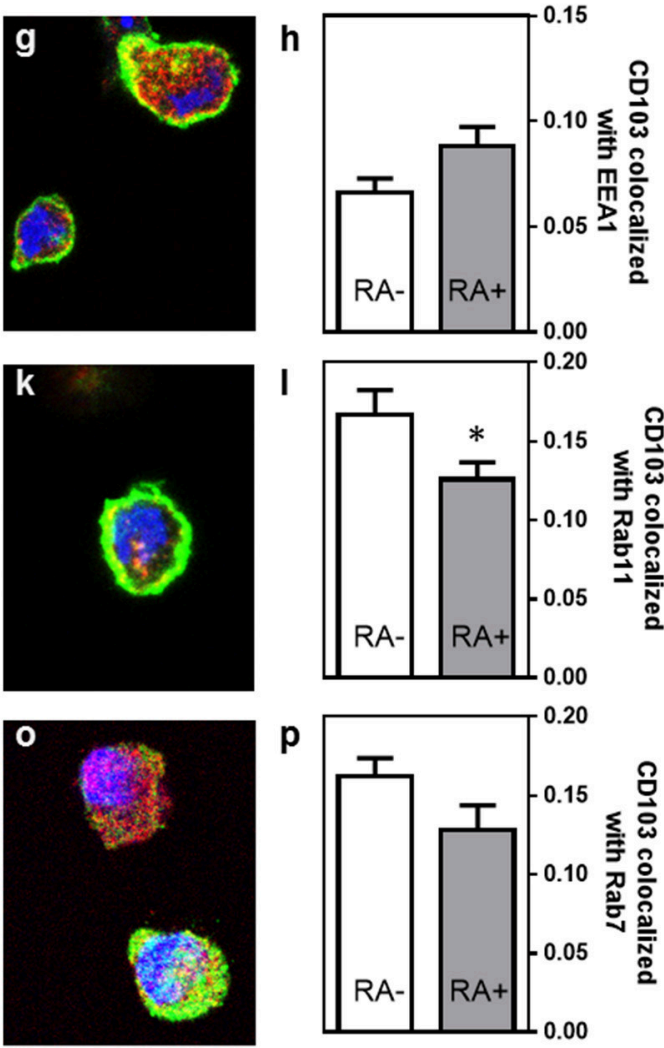

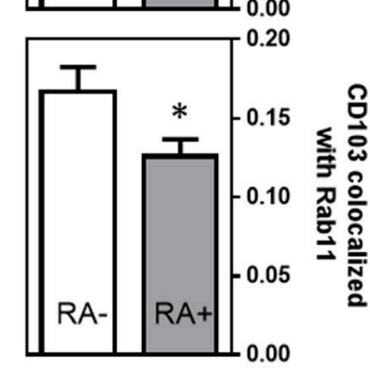

p

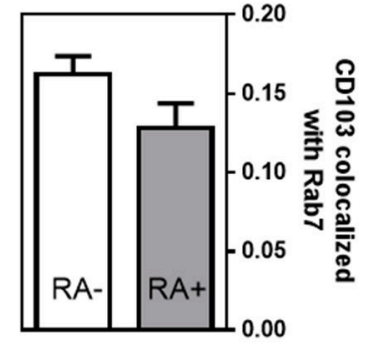

FIGURE 4 | Partial co-localization of CD103 with endosomal markers in human MoDCs. MoDCs generated in medium alone or in the presence of retinoic acid (RA, $100 \mathrm{nM}$ ) were permeabilized and stained with antibodies to CD103 (green) and the following endosomal markers (red): (a-c) clathrin, (e-g) EEA-1, (i-k) Rab11, and (m-o) Rab7a. Images were obtained by confocal microscopy. Co-localization of CD103 with (d) clathrin, (h) EEA-1, (l) Rab11, and (p) Rab7a was calculated as the Manders' colocalization coefficient (M2) using ImageJ. Mean \pm SEM of $10-17$ confocal images obtained from two independent experiments. Bar $=20 \mu \mathrm{m},{ }^{*} P \leq$ $0.05 ;{ }^{* \star} P \leq 0.01$; unpaired Student's $T$-test.

vertical axis of the DCs showed a small, but significant shift in the proportion of CD103 close to the glass surface in RA-treated MoDCs in wells that were coated with E-cadherin compared to serum alone (Figure 6B, $P \leq 0.05$ ). However, this trend was not observed in MoDCs generated in the absence of RA.

On hard surfaces, such as glass slides, adhesion complexes including integrin-dependent interactions influence cell spreading by enabling cells to extend actin-based lamellipodia (40). A previous study had shown that K562 cells transfected with $\alpha \mathrm{E}(\mathrm{CD} 103) \beta 7$ formed epithelial protrusions and migrated on E-cadherin-coated surfaces (41). To determine whether CD103 promotes spreading and adhesion of human
DCs on E-cadherin-positive surfaces, we used RA-treated and untreated MoDCs that were blocked with a CD103 neutralizing antibody or an isotype control antibody. As shown in Figure 6C, RA-treated DCs showed a trend $(P$ $=0.05)$ for increased spreading on E-cadherin. However, DC spreading was not influenced by blocking CD103 on the DCs with a neutralizing antibody. The total number of adhered DCs also did not differ between treatments (data not shown). These results indicate that $\mathrm{CD} 103$ may relocate to the cell surface to engage in E-cadherin binding, but that overall DC adhesion to E-cadherin is largely independent of CD103. 
A

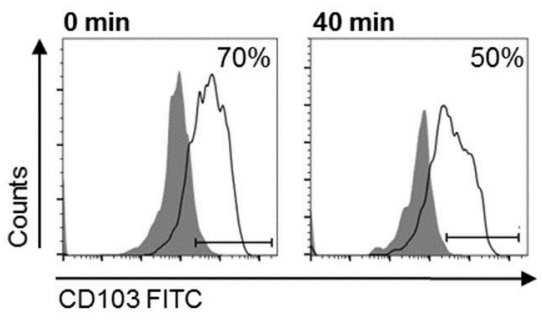

B

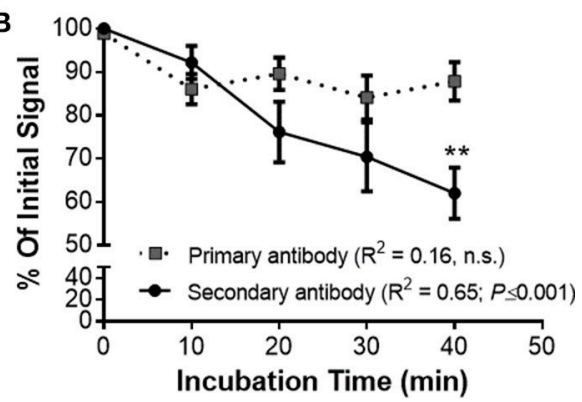

FIGURE 5 | Internalization of surface-expressed CD103 in human MoDCs. Human MoDCs were labeled with an anti-CD103 FITC (mouse IgG1), washed, and chilled with ice-cold buffer. Time zero samples were left on ice, and internalization was initiated in the remaining samples by resuspending the samples in $37^{\circ} \mathrm{C}$ media and incubating them at that temperature for the indicated times. Following incubation, cells were harvested with cold buffer and then left on ice until all samples were collected. Anti-CD103 antibody remaining on the surface of the DCs was detected with a secondary anti-mouse IgG1 antibody. (A) Representative FACS plots and (B) pooled data from four independent experiments show a significant decrease in surface CD103 after 40 min. 2-way ANOVA with Sidak's multiple comparisons.

A
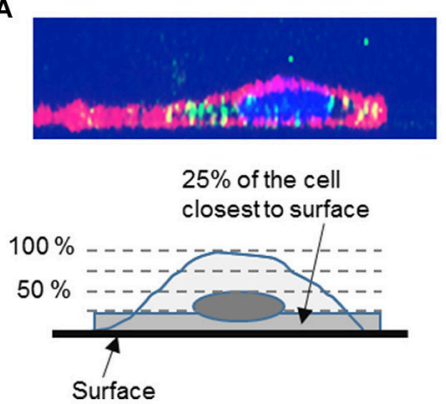

B

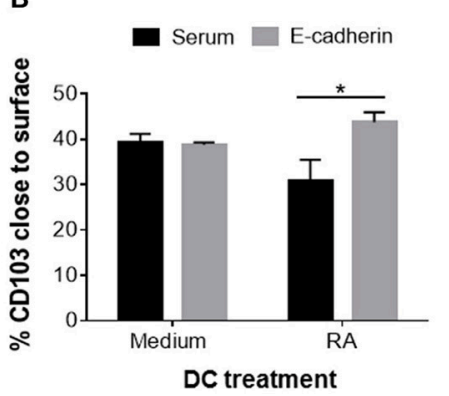

C

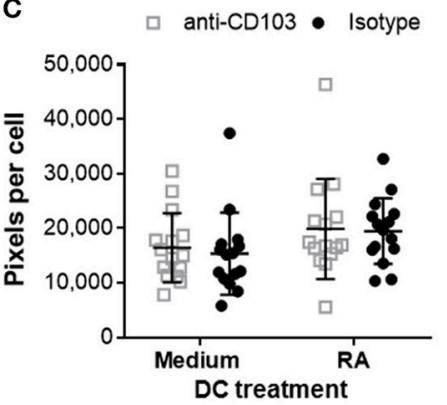

FIGURE 6 | Adhesion of RA-treated MoDCs to E-cadherin-coated surfaces alters distribution of CD103. DC interactions with E-cadherin were analyzed by performing adhesion and spreading assays on glass slides coated with recombinant human E-cadherin. (A,B) RA-treated and untreated MoDCs were added to E-cadherin-coated slides and were incubated at $37^{\circ} \mathrm{C}$ for $40 \mathrm{~min}$. Cells were then fixed, permeabilized and stained for $\mathrm{CD} 103$ expression. Z-stack images $(0.5 \mu \mathrm{m}$ step size) of adherent MoDCs were collected by confocal microscopy and analyzed for the distribution of CD103 in relation to the glass surface. (A) Top panel: orthogonal representation of an immunofluorescently labeled MoDC adhered to a glass surface and analyzed by z-stack confocal imaging. CD11C: red, CD103: green, DAPI nuclear stain: blue. Bottom panel: graphical representation of the image analysis approach. (B) Summarized data from three independent experiments were analyzed. * $P \leq 0.05,1$-way ANOVA with Tukey's post-hoc test. (C) Spreading analysis of DCs on E-cadherin-coated glass slides. Glass slides were first coated with anti-human IgG antibodies and then with recombinant human E-cadherin-Fc. MoDCs generated in the presence of medium alone or $100 \mathrm{nM}$ RA were pre-treated with a CD103 neutralizing antibody or an isotype control antibody for $30 \mathrm{~min}$ at $4^{\circ} \mathrm{C}$. Cells were then added to the slides in the presence of $2 \mathrm{mM}$ Mn ${ }^{2+}$ and incubated at $37^{\circ} \mathrm{C}$ for $40 \mathrm{~min}$. Cell spreading was analyzed by fluorescence microscopy based on HLA-DR ${ }^{+}$pixels per nucleus. Individual data points $(n=15$ areas), mean and SEM from one representative out of 3 independent experiments are shown.

\section{Bivalent Cations Promote DC Adhesion to E-cadherin-Expressing Gastrointestinal Epithelial Cells}

To analyze the interactions between MoDCs and cell-expressed E-cadherin, we performed MoDC adhesion assays with HT-29 cells, a colonic epithelial cell line strongly positive for E-cadherin. Importantly, HT-29 cells have an atypical E-cadherin distribution that involves E-cadherin expression on the apical cell surface (Figures 7A,B), but do not have any mutations in the E-cadherin gene CDH1 $(42,43)$. DCs were incubated on top of HT-29 monolayers, and adherent cells were recovered by trypsinization after $2 \mathrm{~h}$ (Figure 7C). On average, $14.4 \pm 3.7 \%$ of MoDCs were recovered from the cultures as adherent cells (Figure 7D). To determine whether integrins including $\alpha \mathrm{E}$ integrin (CD103) are involved in DC adhesion to the HT-29 cells, we added $1 \mathrm{mM}$ manganese $\left(\mathrm{Mn}^{2+}\right)$, a strong activator of integrins that promotes ligand binding $(44,45)$. Both in RA-treated and untreated MoDCs, addition of $\mathrm{Mn}^{2+}$ significantly increased adhesion to HT-29 cells ( $P \leq 0.001$ and $P \leq 0.05$, respectively). We also added EGTA, which inactivates bivalent cations, such as $\mathrm{Ca}^{2+}, \mathrm{Mg}^{2+}$, and $\mathrm{Mn}^{2+}$ that are involved in integrin- and $\mathrm{E}$ cadherin-dependent interactions. EGTA significantly decreased the number of both and RA-treated and untreated DCs that were recovered from the co-cultures $(P \leq 0.05$ and $P \leq 0.01$, respectively). Although there was a trend for increased adhesion in RA-treated MoDCs, RA had no significant effect on DC binding to HT-29 cells, similar to our observations from the spreading analysis (Figure 6). Interestingly, co-culture with the HT-29 slightly increased surface expression of CD103 on the MoDCs (Figure 7E, $P=0.056$ ). 
A

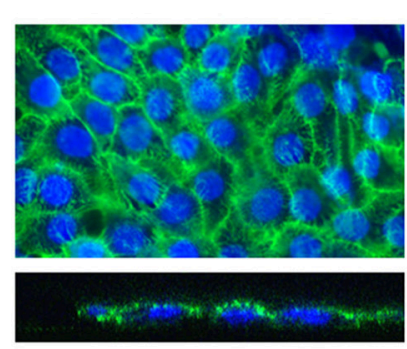

B

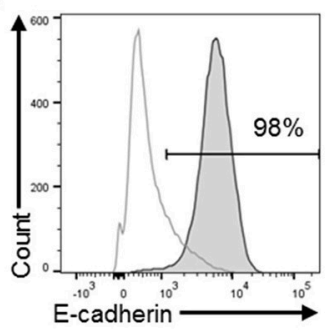

C

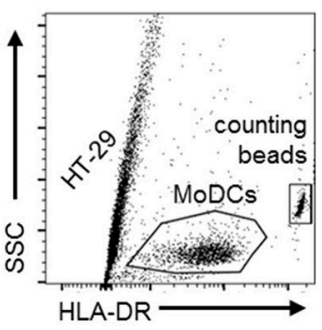

D

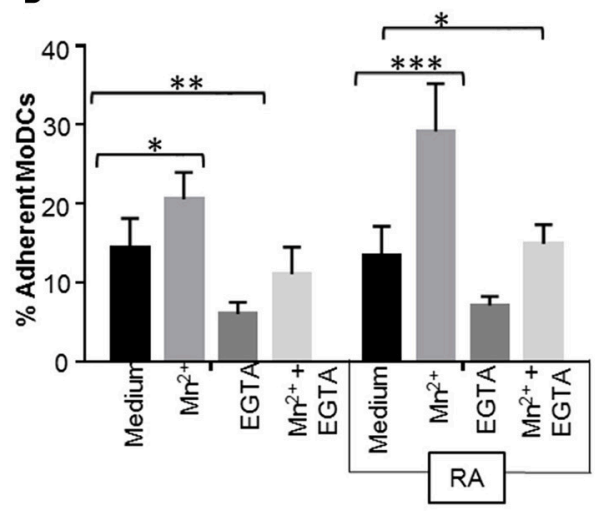

E

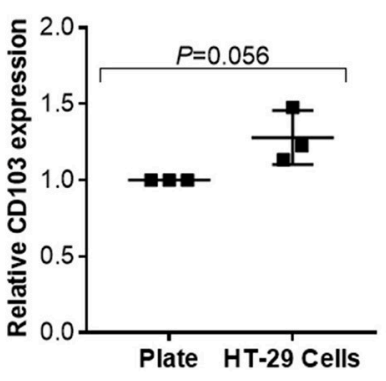

$\mathbf{F}$

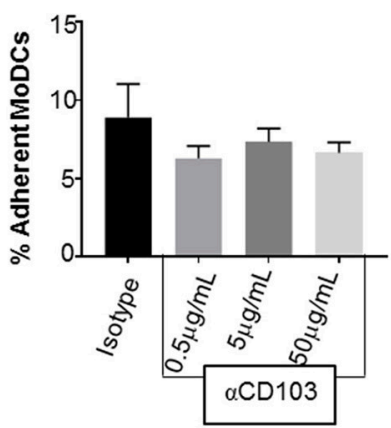

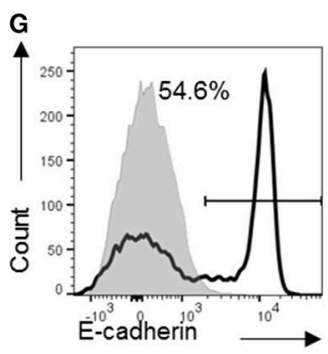

$\mathbf{H}$

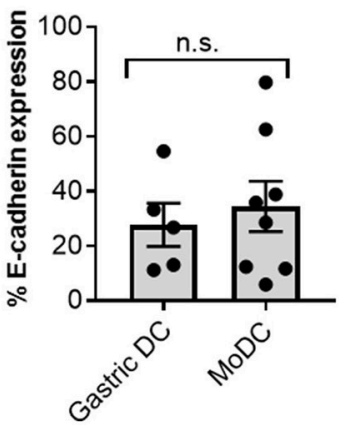

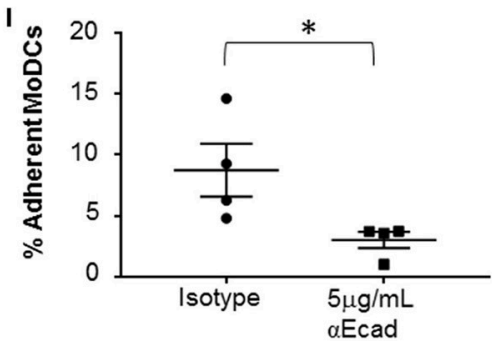

FIGURE 7 | CD103 is not a major mediator of DC adhesion to E-cadherin-expressing epithelial cells. To analyze MoDC binding to E-cadherin expressed by epithelial cells, MoDCs were added to confluent monolayers of HT-29 cells for $2 \mathrm{~h}$. Non-adherent cells were then removed by gentle washing, the remaining cells were collected by trypsinization, and the number of adherent DCs was determined using counting beads and HLA-DR-labeling of the DCs. (A) Confocal analysis of an HT-29 monolayer shows E-cadherin expression on the luminal surface. Top panel: maximum Z-projection; bottom panel: orthogonal view. Nuclei are labeled with DRAQ5 (blue). (B) Representative FACS histogram of E-cadherin expression on HT-29 cells. Gray line: isotype control; dark gray filled: anti-E-cadherin. (C) Gating strategy for counting adherent MoDCs following co-culture with HT-29 cells. (D) Percentage of MoDCs adherent to HT-29 cells in the presence of Mn ${ }^{2+}$, EGTA, or Mn ${ }^{2+}+$ EGTA $(n=6)$. RA indicates that cells were derived in the presence of 100 nM RA. ${ }^{*} P \leq 0.05,{ }^{\star \star} P \leq 0.01,{ }^{\star \star \star} P \leq 0.001$; 2 -way ANOVA with Dunnett's multiple comparisons. (E) Normalized CD103 expression on MoDCs after recovery from HT-29 co-cultures (with $\mathrm{Mn}^{2+}$ ). Data from three independent experiments, paired, one-tailed Student's $t$-test. (F) MoDCs were incubated with an isotype control antibody or the indicated concentrations of anti-CD103 antibody before and during co-culture with HT-29 cells, and the number of adherent DCs was determined. $N=3,{ }^{*} P \leq 0.05$; unpaired, two-tailed $T$-test. $(\mathbf{G}, \mathbf{H})$ representative histogram and pooled data for E-cadherin expression on human gastric $(n=5)$ and MoDCs $(n=8)$. (I) MoDCs were treated with anti-E-cadherin antibody before and during co-culture with HT-29 cells, and the number of adherent DCs was determined. $N=4,{ }^{*} P \leq 0.05$; unpaired, two-tailed Student's $t$-test.

\section{Neutralization of DC CD103 Does Not Inhibit Adhesion to E-cadherin Expressing Epithelial Cells}

To specifically assess the involvement of CD103 in the interactions between DCs and epithelial cells, RA-treated MoDCs were blocked with a CD103 neutralizing antibody prior to adding the cells to the HT-29 monolayer in the presence of $\mathrm{Mn}^{2+}$. To avoid loss of blocking activity due to CD103 internalization, excess antibody was left in the cell culture medium during the adhesion assays. However, no decrease in DC adhesion to the HT-29 cells was seen with a wide range of antibody concentrations (Figure 7F). 


\section{Homotypic E-cadherin Interactions May be Involved in DC Binding to E-cadherin on Gastrointestinal Epithelial Cells}

To form adherens junctions, E-cadherin undergoes homotypic interactions with E-cadherin expressed on other cells (46), and DCs have been shown to express E-cadherin in previous studies (47-49). Our FACS analysis revealed that subsets of both human gastric DCs and MoDCs expressed E-cadherin (Figures 7G,H), independent of RA treatment (Supplemental Figure 2). Thus, E-cadherin-E-cadherin interactions may contribute to DCepithelial cell interactions. Indeed, pre-treatment of the MoDCs with an E-cadherin neutralizing antibody significantly decreased DC adhesion to HT-29 monolayers (Figure 7I). However, when we compared MoDC adhesion to HT-29 cells with adhesion to AGS cells, which lack E-cadherin expression, we found that a significantly higher number of DCs adhered to the AGS cells than the HT-29 cells (Supplemental Figure 3, $P \leq 0.01$ ). Interestingly, binding to AGS cells decreased when DCs were generated in the presence of RA. Overall, these data suggest that both E-cadherindependent and integrin-dependent mechanisms contribute to DC binding to the gastrointestinal epithelium, but that CD103E-cadherin interactions are only minor contributors.

\section{DISCUSSION}

$\mathrm{CD} 103$ ( $\alpha \mathrm{E}$ integrin) is widely used as a maker for DC subsets in humans and mice (29), but the functional role of CD103 for the DCs has attracted little investigative attention. We here sought to elucidate whether CD103 could mediate DC-epithelial cell interactions in the human gastric mucosa. A number of previous reports had speculated that CD103 might mediate adhesion of gastrointestinal DCs to E-cadherin expressed in the epithelial layer (15-17), similar to the mechanism shown for the retention of intraepithelial lymphocytes within the epithelial compartment $(22,50)$. Studies from our laboratory have shown that DCs in the gastric mucosa are exposed to RA generated by gastric epithelial cells, and that RA induces CD103 expression in human MoDCs $(14,26)$. Our results from the present study suggest that CD103 is engaged upon binding of primary DCs to gastrointestinal epithelium, but is not a major mediator of adhesion.

One specific consideration when investigating CD103 in human gastric DCs was that $<10 \%$ of the DCs expressed CD103 on their surface, as we have previously shown $(14,26)$. However, based on the detection of intracellular CD103 ( $\alpha \mathrm{E}$ integrin), we hypothesized that these intracellular pools could be recruited to the cell surface for dynamic interactions with their ligands. Thus, integrins $\alpha 5 \beta 1, \alpha 6 \beta 4, \alpha \mathrm{M} \beta 1$, and $\alpha 4 \beta 1$ are continuously recycled through endosomal pathways during cell migration (33). However, not all integrins participate in the endocytotic cycle, and some integrins are recycled at only low rates (31). Indeed, we here confirmed that $\alpha 4$ integrin, which, like $\alpha \mathrm{E}$ integrin, pairs with $\beta 7$ integrin, was not expressed intracellularly. Our report is the first to demonstrate that CD103 in human DCs is expressed in endosomal compartments and recirculates through the cell membrane, suggesting that $\alpha \mathrm{E}$ integrin recycling occurs in human DCs. It has been proposed that motile cells, such as DCs performing immunosurveillance functions, may require more trafficking of integrins and therefore contain a higher intracellular proportion (51). We demonstrated that $40 \%$ of surface CD103 was internalized in $<1 \mathrm{~h}$. Moreover, $23-30 \%$ of CD103 co-localized with clathrin, consistent with the established role of clathrin in the endocytic recycling of integrin-mediated adhesions (52). A lower percentage of CD103 co-localized with the early endosome antigen 1 (EEA-1, 7\%) and Rab11 (17\%), a marker for long-loop endosomal recycling. Notably, previous publications have similarly reported co-localization co-efficients between 5 and 30\% for integrins and endosomal markers in cells that were not specifically treated to enhance endosomal trafficking. Thus, Ezratty et al. (52) reported that $20-25 \%$ of $\beta 1$ integrin co-localized with Rab5. In a publication by the Goldenring group, a Manders' co-localization co-efficient of $>0.2$ (>20\%) for co-localization of Rab25 with $\beta 1$ and $\alpha 5$ integrins was considered high (53). Gu et al. (54) from the Brenner lab analyzed co-localization of $\beta 3$ integrin with endosomal markers and found between 2 and $8 \%$ of co-localization with EEA-1, Rab4, 5, and 11 at baseline, with increased co-localization upon PDGF-stimulated micropinocytosis. Khandelwal et al. (55) used a functional endocytosis assay with fluorescently labeled cargo and detected co-localization co-efficients of 10 and $20 \%$ for the endosomal cargo with EEA-1 and Rab11, respectively, and Karjalainen et al. (56) analyzed co-localization of $\alpha 2$ integrin with caveolin and detected 5-10\% of co-localization at baseline. Therefore, we consider our observed co-localization of CD103 with the endosomal markers to be biologically relevant. Colocalization of CD103/integrin $\alpha \mathrm{E}$ with clathrin, EEA1, and Rab11 suggests that integrin $\alpha \mathrm{E}$ undergoes canonical trafficking similar to $\alpha 5 \beta 1$ integrin (57). However, the fact that CD103 also was co-localized with the late endosomal marker Rab7a may indicate that a proportion of intracellular CD103 is targeted for lysosomal degradation rather than recycling to the cell surface. Notably, when added together, $<60 \%$ of all CD103 co-localized with any endosomal marker, suggesting that a significant proportion of $\mathrm{CD} 103$ is present at sites that are not endosomal compartments. These might represent newly synthesized CD103 molecules in the endoplasmic reticulum or in the Golgi apparatus. Interestingly, RA treatment of the MoDCs led to increased co-localization with clathrin and EEA-1, but decreased co-localization with Rab11 and Rab7a. Thus, RA seems to both upregulate CD103 expression $(26,58)$ and alter its trafficking. Overall, our results suggest that, even on cells with low surface CD103 expression, CD103 may be recruited from endosomal pools for dynamic binding to epithelial E-cadherin or other ligands.

In support of a role for CD103 in human DC-epithelial interactions, we here showed significantly increased expression of CD103 on human HLA-DR ${ }^{+}$DCs that were integrated into the gastric epithelial layer. Moreover, Z-stack analysis of MoDCs bound to E-cadherin-coated glass slides showed significant redistribution of DC-expressed CD103 to the E-cadherin positive interface, albeit only in RA-treated cells. In addition, in vitro adhesion assays to E-cadherin-expressing HT-29 cells revealed a dependence on bivalent cations including manganese, consistent with an integrin-dependent mechanism (45). Conversely, when 
MoDCs were treated with a CD103 neutralizing antibody, adhesion to E-cadherin-positive HT-29 cells or to E-cadherincoated glass slides was unaffected, arguing against a major role of CD103 in mediating DC binding to the gastrointestinal epithelium. Notably, while internalization of CD103 with bound blocking antibody may have decreased the efficiency of the neutralization, this would not be expected to completely abrogate functional activity of the blocking antibody, especially since a high antibody concentration $(5 \mu \mathrm{g} / \mathrm{mL})$ was used and additional antibody was present in the culture medium during the assay. Also, RA treatment, which increases MoDC CD103 expression, did not significantly influence MoDC binding to E-cadherinexpressing HT-29 cells or spreading on E-cadherin-coated glass surface, corroborating the results from the antibody neutralization experiments. Thus, adhesion of human DCs to gastrointestinal epithelia does not appear to be driven by CD103E-cadherin interactions. Notably, we used high expression of HLA-DR to detect DCs in human gastric tissue sections, since no other more specific general DC marker has been identified for human stomach $(2,28)$. In the murine gastric mucosa, $\mathrm{CX}_{3} \mathrm{CR} 1^{+}$ $\mathrm{CD}_{103}{ }^{-}$macrophages, and $\mathrm{CD}_{103}{ }^{-}$DCs were able to sample H. pylori bacteria, whereas bacterial uptake by $\mathrm{CD}_{103^{+}} \mathrm{DCs}$ could not be detected (25), which also does not support our original hypothesis that $\mathrm{CD} 103$ positions gastric mononuclear cells at the epithelial interface for luminal $H$. pylori uptake. Along the same lines, an earlier report that investigated intraepithelial DCs in murine small intestine, the spatial relationship of murine intestinal DCs with the epithelium was not altered in CD103 knockout mice (59), whereas the number of IELs was significantly reduced in these animals (60). Together, these observations indicate that there are functional differences between $\mathrm{T}$ cell and DC-expressed CD103.

Our adhesion experiments did show that antibody inhibition of DC-expressed E-cadherin significantly suppressed DC binding to HT-29 cells, suggesting a role for homotypic E-cadherin-Ecadherin interactions. Thus, our results corroborate previous studies that showed Langerhans cells and other DCs of the skin and female genital tract interact with the epithelium through E-cadherin-E-cadherin binding $(47,61,62)$. Notably, although homotypic E-cadherin interactions are calcium dependent, it appears that calcium can be replaced by the bivalent transitional elements manganese $\left(\mathrm{Mn}^{2+}\right)$ and cadmium $\left(\mathrm{Cd}^{2+}\right)$ (63), which would explain the observed increase in adhesion in the presence of $\mathrm{Mn}^{2+}$. The significant decrease in MoDC HT-29 adhesion in the presence of EGTA is consistent with either homotypic E-cadherin-E-cadherin interactions, which are calcium-dependent (64), or heterotypic E-cadherin interactions with $\alpha \mathrm{E}$ integrin, which is activated by manganese $\left(\mathrm{Mn}^{2+}\right)$ (65). Since E-cadherin is widely expressed on mucosal epithelial cells, it is a likely candidate for mediating the retention of motile immune cells at the epithelial barrier, and additional heterotypic E-cadherin ligands with expression on DCs including killer cell lectin-like receptor G1 (KLRG1) have been identified $(22,49,66,67)$. Surprisingly, MoDC adhesion to E-cadherin negative AGS cells was significantly higher than adhesion to HT-29 cells. These results suggest that DC adhesion to the gastrointestinal epithelium may involve additional molecular interactions independent of $\mathrm{CD} 103$ or E-cadherin, such as tight junction proteins $(11,68)$ and other integrins. Notably, all myeloid cells including DCs express $\beta 2$ integrin (CD18). CD18 forms heterodimers with CD11a, CD11b, and CD11c (69) and contributes to cell-cell contact formation by binding to intracellular adhesion molecules (ICAMs), which may be expressed on gastric and intestinal epithelial cells $(70,71)$. Notably, adhesion of DCs to epithelial cells via $\beta 2$ integrins would be consistent with our experimental observations that showed increased binding in the presence of $\mathrm{Mn}^{2+}$ and decreased binding in the presence of EGTA. Whether $\beta 2$ integrins are major mediators of DC adhesion to the human gastric epithelium will be a subject of future studies.

If the interactions between DC-expressed CD103 and epithelial cells that we observed in human gastric tissue section do not result in strong adhesion, one might question the relevance of these interactions. However, engagement of CD103 by epithelial E-cadherin may lead to outside-in signaling through the cytoplasmic portion of the integrin (72). Previous studies have shown that in cytotoxic $\mathrm{T}$ cells, engagement of E-cadherin by $\mathrm{CD} 103$ triggers the phosphorylation of PLC $\gamma 1$ and ERK1/2 (73), and engagement of CD103 by an anti-CD103 antibody can enhance $\mathrm{T}$ cell proliferation (74). Therefore, interactions between DC CD103 and epithelial E-cadherin could regulate certain DC functional characteristics through the activation of intracellular signaling cascades.

In summary, our study has provided novel insights in the regulation and function of $\mathrm{CD} 103$ (E integrin) in human DCs. We show that, like other integrins in motile cells, CD103 undergoes endosomal trafficking, which likely enables dynamic interactions between CD103 and its ligands. Our results also corroborate previous reports (59) that CD103 is not essential for the retention of DCs at gastrointestinal epithelial sites. The mechanisms by which CD103 on DCs in the human gastrointestinal tract interact with epithelial cells may be more subtle than simple adhesive interactions and requires further experimental exploration.

\section{ETHICS STATEMENT}

This study was carried out in accordance with the recommendations of the U.S. Department of Health and Human Services' Policy for Protection of Human Research Subjects (45 CFR 46) with written informed consent from all subjects. All subjects gave written informed consent in accordance with the Declaration of Helsinki. The protocol was approved by the Institutional Review Boards of Montana State University and the University of Alabama at Birmingham.

\section{AUTHOR CONTRIBUTIONS}

DB and SS planned and oversaw the experiments. DB, SS, MR, BS, JD, TS, and RV performed the experiments. DB, PS, and LS initiated the project, critically discussed the data and obtained 
funding. DB, SS, and MR analyzed the data. MR, SS, and DB wrote the manuscript. All authors provided feedback on the manuscript.

\section{ACKNOWLEDGMENTS}

Funding for our study was provided by the National Institutes of Health grants K01 DK097144 (DB); R03 DK107960 (DB) and startup funding from Montana State University. We greatly appreciate support from the National Institutes of Health IDeA Program grant GM110732, and equipment grants from the M. J. Murdock Charitable Trust (2016028:MNL:8/25/2016) and the Montana State University Agricultural Experimental Station for the Flow Cytometry Core Facility at Montana State University. LS received funding from the Broad Medical Foundation and the Crohn's and Colitis Foundation of America, and PS also received funding from the Crohn's and Colitis Foundation of America that supported this study. We greatly acknowledge Dr. Heini Miettinen-Granger's input on experimental design and her comments on our final manuscript. Dr. Agnieszka Rynda-Apple's critical feedback on our manuscript is likewise greatly appreciated. We would also like to thank all our human volunteers for donating blood samples for this study.

\section{REFERENCES}

1. Necchi V, Manca R, Ricci V, Solcia E. Evidence for transepithelial dendritic cells in human H. pylori active gastritis. Helicobacter (2009) 14:208-22. doi: 10.1111/j.1523-5378.2009.00679.x

2. Bimczok D, Clements RH, Waites KB, Novak L, Eckhoff DE, Mannon PJ, et al. Human primary gastric dendritic cells induce a Th1 response to H. pylori. Mucosal Immunol. (2010) 3:260-9. doi: 10.1038/mi.2010.10

3. Kao JY, Zhang M, Miller MJ, Mills JC, Wang B, Liu M, et al. Helicobacter pylori immune escape is mediated by dendritic cell-induced Treg skewing and Th17 suppression in mice. Gastroenterology (2010) 138:1046-54. doi: 10.1053/j.gastro.2009.11.043

4. Shiu J, Blanchard TG. Dendritic cell function in the host response to Helicobacter pylori infection of the gastric mucosa. Pathog Dis. (2013) 67:4653. doi: 10.1111/2049-632X.12014

5. Moss SF, Malfertheiner P. Helicobacter and gastric malignancies. Helicobacter (2007) 12(Suppl. 1):23-30. doi: 10.1111/j.1523-5378.2007.00539.x

6. Hitzler I, Oertli M, Becher B, Agger EM, Muller A. Dendritic cells prevent rather than promote immunity conferred by a helicobacter vaccine using a mycobacterial adjuvant. Gastroenterology (2011) 141:186-196, 196.e181. doi: 10.1053/j.gastro.2011.04.009

7. Amieva M, Peek RM Jr. Pathobiology of Helicobacter pylori-induced gastric cancer. Gastroenterology (2016) 150:64-78. doi: 10.1053/j.gastro.2015. 09.004

8. Harris PR, Wright SW, Serrano C, Riera F, Duarte I, Torres J, et al. Helicobacter pylori gastritis in children is associated with a regulatory $\mathrm{T}$ cell response. Gastroenterology (2008) 134:491-9. doi: 10.1053/j.gastro.2007. 11.006

9. Robinson K, Kenefeck R, Pidgeon EL, Shakib S, Patel S, Polson RJ, et al. Helicobacter pylori-induced peptic ulcer disease is associated with inadequate regulatory $\mathrm{T}$ cell responses. Gut (2008) 57:1375-85. doi: 10.1136/gut.2007.137539

10. Serrano C, Wright SW, Bimczok D, Shaffer CL, Cover TL, Venegas A, et al. Downregulated Th17 responses are associated with reduced gastritis in Helicobacter pylori-infected children. Mucosal Immunol. (2013) 6:950-9. doi: $10.1038 / \mathrm{mi} .2012 .133$

\section{SUPPLEMENTARY MATERIAL}

The Supplementary Material for this article can be found online at: https://www.frontiersin.org/articles/10.3389/fimmu. 2018.02989/full\#supplementary-material

Supplemental Figure 1 | Coating of glass surfaces with rh E-cadherin. Untreated or poly-L lysine-coated wells of a glass bottom 96 well plate were incubated with recombinant human E-cadherin $(1 \mu \mathrm{g} / \mathrm{mL})$ in PBS for $60 \mathrm{~min}$. Following a blocking step with $10 \%$ human serum, and several washes, E-cadherin bound to the plate was detected using an anti-E-cadherin antibody and visualized using an alkaline phosphatase detection system. Left panel: mean absorption ( $405 \mathrm{~nm}) \pm$ SEM of duplicate wells. Right panel: plate image.

Supplemental Figure 2 | Retinoic acid significantly increases expression of CD103, but not E-cadherin in human MoDCs. MoDCs were treated with $100 \mathrm{nM}$ RA and surface expression of E-cadherin (left panel, $n=12$ ) and CD103 (right panel, $n=13$ ) were analyzed with flow cytometry. ${ }^{*} P \leq 0.05$; unpaired, two-tailed T-test.

Supplemental Figure $\mathbf{3}$ | Strong adhesion of MoDCs to E-cadherin negative AGS cells. Top panel: confocal analysis of an AGS and an HT-29 monolayer shows surface E-cadherin expression (green) by the HT-29, but not by AGS cells. Bottom panel: RA-treated or untreated MoDCs were added to confluent monolayers of AGS or HT-29 cells for $2 \mathrm{~h}$. Non-adherent cells were then removed by gentle washing, the remaining cells were collected by trypsinization, and the number of adherent DCs was determined using counting beads and CD11c-labeling of the DCs. Mean \pm SEM of three independent experiments. Data were analyzed by ANOVA with Tukey's post-hoc test. a, b: different letters indicate significantly different values $(P \leq 0.05)$.

11. Rescigno M, Urbano M, Valzasina B, Francolini M, Rotta G, Bonasio R, et al. Dendritic cells express tight junction proteins and penetrate gut epithelial monolayers to sample bacteria. Nat Immunol. (2001) 2:361-7. doi: $10.1038 / 86373$

12. Iliev ID, Mileti E, Matteoli G, Chieppa M, Rescigno M. Intestinal epithelial cells promote colitis-protective regulatory T-cell differentiation through dendritic cell conditioning. Mucosal Immunol. (2009) 2:340-50. doi: $10.1038 / \mathrm{mi} .2009 .13$

13. Iliev ID, Spadoni I, Mileti E, Matteoli G, Sonzogni A, Sampietro GM, et al. Human intestinal epithelial cells promote the differentiation of tolerogenic dendritic cells. Gut (2009) 58:1481-9. doi: 10.1136/gut.2008.175166

14. Bimczok D, Kao JY, Zhang M, Cochrun S, Mannon P, Peter S, et al. Human gastric epithelial cells contribute to gastric immune regulation by providing retinoic acid to dendritic cells. Mucosal Immunol. (2015) 8:533-44. doi: $10.1038 / \mathrm{mi} .2014 .86$

15. Hadley GA, Higgins JM. Integrin alphaEbeta7: molecular features and functional significance in the immune system. Adv Exp Med Biol. (2014) 819:97-110. doi: 10.1007/978-94-017-9153-3_7

16. Watchmaker PB, Lahl K, Lee M, Baumjohann D, Morton J, Kim SJ, et al. Comparative transcriptional and functional profiling defines conserved programs of intestinal DC differentiation in humans and mice. Nat Immunol. (2014) 15:98-108. doi: 10.1038/ni.2768

17. Habtezion A, Nguyen LP, Hadeiba H, Butcher EC. Leukocyte trafficking to the small intestine and colon. Gastroenterology (2016) 150:340-54. doi: 10.1053/j.gastro.2015.10.046

18. Haniffa M, Collin M, Ginhoux F. Ontogeny and functional specialization of dendritic cells in human and mouse. Adv Immunol. (2013) 120:1-49. doi: 10.1016/B978-0-12-417028-5.00001-6

19. Guilliams M, Ginhoux F, Jakubzick C, Naik SH, Onai N, Schraml BU, et al. Dendritic cells, monocytes and macrophages: a unified nomenclature based on ontogeny. Nat Rev Immunol. (2014) 14:571-8. doi: 10.1038/nri3712

20. Segura E. Review of mouse and human dendritic cell subsets. Methods Mol Biol. (2016) 1423:3-15. doi: 10.1007/978-1-4939-3606-9_1

21. Scott CL, Aumeunier AM, Mowat AM. Intestinal CD103+ dendritic cells: master regulators of tolerance? Trends Immunol. (2011) 32:412-9. doi: 10.1016/j.it.2011.06.003 
22. Cepek KL, Shaw SK, Parker CM, Russell GJ, Morrow JS, Rimm DL, et al. Adhesion between epithelial cells and T lymphocytes mediated by E-cadherin and the alpha E beta 7 integrin. Nature (1994) 372:190-3. doi: 10.1038/372190a0

23. Higgins JM, Cernadas M, Tan K, Irie A, Wang J, Takada Y, et al. The role of alpha and beta chains in ligand recognition by beta 7 integrins. J Biol Chem. (2000) 275:25652-64. doi: 10.1074/jbc.M001228200

24. Corps E, Carter C, Karecla P, Ahrens T, Evans P, Kilshaw P. Recognition of Ecadherin by integrin alpha(E)beta(7): requirement for cadherin dimerization and implications for cadherin and integrin function. J Biol Chem. (2001) 276:30862-70. doi: 10.1074/jbc.M101712200

25. Arnold IC, Zhang X, Urban S, Artola-Boran M, Manz MG, Ottemann KM, et al. NLRP3 controls the development of gastrointestinal CD11b(+) dendritic cells in the steady state and during chronic bacterial infection. Cell Rep. (2017) 21:3860-72. doi: 10.1016/j.celrep.2017.12.015

26. Roe MM, Swain S, Sebrell TA, Sewell MA, Collins MM, Perrino BA, et al. Differential regulation of CD103 (alphaE integrin) expression in human dendritic cells by retinoic acid and Toll-like receptor ligands. J Leukoc Biol. (2017) 101:1169-80. doi: 10.1189/jlb.1MA0316-131R

27. Viladomiu M, Bassaganya-Riera J, Tubau-Juni N, Kronsteiner B, Leber A, Philipson CW, et al. Cooperation of gastric mononuclear phagocytes with helicobacter pylori during colonization. J Immunol. (2017) 198:3195-204. doi: 10.4049/jimmunol.1601902

28. Bimczok D, Grams JM, Stahl RD, Waites KB, Smythies LE, Smith PD. Stromal regulation of human gastric dendritic cells restricts the Th1 response to Helicobacter pylori. Gastroenterology (2011) 141:929-38. doi: 10.1053/j.gastro.2011.06.006

29. Del Rio ML, Bernhardt G, Rodriguez-Barbosa JI, Forster R. Development and functional specialization of CD103+ dendritic cells. Immunol Rev. (2010) 234:268-81. doi: 10.1111/j.0105-2896.2009.00874.x

30. Agace WW, Persson EK. How vitamin A metabolizing dendritic cells are generated in the gut mucosa. Trends Immunol. (2012) 33:42-8. doi: $10.1016 /$ j.it.2011.10.001

31. Bretscher MS. Circulating integrins: alpha 5 beta 1 , alpha 6 beta 4 and Mac-1, but not alpha 3 beta 1, alpha 4 beta 1 or LFA-1. EMBO J. (1992) 11:405-10. doi: 10.1002/j.1460-2075.1992.tb05068.x

32. Bridgewater RE, Norman JC, Caswell PT. Integrin trafficking at a glance. J Cell Sci. (2012) 125:3695-701. doi: 10.1242/jcs.095810

33. Paul NR, Jacquemet G, Caswell PT. Endocytic trafficking of integrins in cell migration. Curr Biol. (2015) 25:R1092-105. doi: 10.1016/j.cub.2015.09.049

34. Bolte S, Cordelieres FP. A guided tour into subcellular colocalization analysis in light microscopy. J Microsc. (2006) 224:213-32. doi: 10.1111/j.1365-2818.2006.01706.x

35. Dunn KW, Kamocka MM, Mcdonald JH. A practical guide to evaluating colocalization in biological microscopy. Am J Physiol Cell Physiol. (2011) 300:C723-42. doi: 10.1152/ajpcell.00462.2010

36. Chen PW, Luo R, Jian X, Randazzo PA. The Arf6 GTPaseactivating proteins ARAP2 and ACAP1 define distinct endosomal compartments that regulate integrin alpha5betal traffic. $J$ Biol Chem. (2014) 289:30237-48. doi: 10.1074/jbc.M114. 596155

37. Rainero E, Norman JC. Late endosomal and lysosomal trafficking during integrin-mediated cell migration and invasion: cell matrix receptors are trafficked through the late endosomal pathway in a way that dictates how cells migrate. Bioessays (2013) 35:523-32. doi: 10.1002/bies.201200160

38. Maritzen T, Schachtner H, Legler DF. On the move: endocytic trafficking in cell migration. Cell Mol Life Sci. (2015) 72:2119-34. doi: 10.1007/s00018-015-1855-9

39. Guerra F, Bucci C. Multiple roles of the small GTPase Rab7. Cells (2016) 5:E34. doi: 10.3390/cells5030034

40. Vernerey FJ, Farsad M. A mathematical model of the coupled mechanisms of cell adhesion, contraction and spreading. J Math Biol. (2014) 68:989-1022. doi: 10.1007/s00285-013-0656-8

41. Schlickum S, Sennefelder H, Friedrich M, Harms G, Lohse MJ, Kilshaw P, et al. Integrin alpha $\mathrm{E}(\mathrm{CD} 103)$ beta 7 influences cellular shape and motility in a ligand-dependent fashion. Blood (2008) 112:619-25. doi: 10.1182/blood-2008-01-134833
42. Efstathiou JA, Liu D, Wheeler JM, Kim HC, Beck NE, Ilyas M, et al. Mutated epithelial cadherin is associated with increased tumorigenicity and loss of adhesion and of responsiveness to the motogenic trefoil factor 2 in colon carcinoma cells. Proc Natl Acad Sci USA. (1999) 96:2316-21. doi: 10.1073/pnas.96.5.2316

43. Gout S, Marie C, Laine M, Tavernier G, Block MR, Jacquier-Sarlin M. Early enterocytic differentiation of HT-29 cells: biochemical changes and strength increases of adherens junctions. Exp Cell Res. (2004) 299:498-510. doi: 10.1016/j.yexcr.2004.06.008

44. Ye F, Kim C, Ginsberg MH. Reconstruction of integrin activation. Blood (2012) 119:26-33. doi: 10.1182/blood-2011-04-292128

45. Zhang K, Chen J. The regulation of integrin function by divalent cations. Cell Adh Migr. (2012) 6:20-9. doi: 10.4161/cam.18702

46. Van Roy F, Berx G. The cell-cell adhesion molecule E-cadherin. Cell Mol Life Sci. (2008) 65:3756-88. doi: 10.1007/s00018-008-8281-1

47. Jakob T, Brown MJ, Udey MC. Characterization of E-cadherin-containing junctions involving skin-derived dendritic cells. J Invest Dermatol. (1999) 112:102-8. doi: 10.1046/j.1523-1747.1999.00475.x

48. Riedl E, Stockl J, Majdic O, Scheinecker C, Rappersberger K, Knapp W, et al. Functional involvement of E-cadherin in TGF-beta 1-induced cell cluster formation of in vitro developing human Langerhans-type dendritic cells. $J$ Immunol. (2000) 165:1381-6. doi: 10.4049/jimmunol.165.3.1381

49. Van Den Bossche J, Malissen B, Mantovani A, De Baetselier P, Van Ginderachter JA. Regulation and function of the E-cadherin/catenin complex in cells of the monocyte-macrophage lineage and DCs. Blood (2012) 119:1623-33. doi: 10.1182/blood-2011-10-384289

50. Schon MP, Arya A, Murphy EA, Adams CM, Strauch UG, Agace WW, et al. Mucosal T lymphocyte numbers are selectively reduced in integrin alpha $\mathrm{E}$ (CD103)-deficient mice. J Immunol. (1999) 162:6641-9.

51. Lobert VH, Brech A, Pedersen NM, Wesche J, Oppelt A, Malerod L, et al. Ubiquitination of alpha 5 beta 1 integrin controls fibroblast migration through lysosomal degradation of fibronectin-integrin complexes. Dev Cell (2010) 19:148-59. doi: 10.1016/j.devcel.2010.06.010

52. Ezratty EJ, Bertaux C, Marcantonio EE, Gundersen GG. Clathrin mediates integrin endocytosis for focal adhesion disassembly in migrating cells. J Cell Biol. (2009) 187:733-47. doi: 10.1083/jcb.200904054

53. Krishnan M, Lapierre LA, Knowles BC, Goldenring JR. Rab25 regulates integrin expression in polarized colonic epithelial cells. Mol Biol Cell (2013) 24:818-31. doi: 10.1091/mbc.e12-10-0745

54. Gu Z, Noss EH, Hsu VW, Brenner MB. Integrins traffic rapidly via circular dorsal ruffles and macropinocytosis during stimulated cell migration. J Cell Biol. (2011) 193:61-70. doi: 10.1083/jcb.201007003

55. Khandelwal P, Ruiz WG, Apodaca G. Compensatory endocytosis in bladder umbrella cells occurs through an integrin-regulated and RhoA- and dynamindependent pathway. EMBO J. (2010) 29:1961-75. doi: 10.1038/emboj.2010.91

56. Karjalainen M, Kakkonen E, Upla P, Paloranta H, Kankaanpaa P, Liberali $\mathrm{P}$, et al. A Raft-derived, Pak1-regulated entry participates in alpha2beta1 integrin-dependent sorting to caveosomes. Mol Biol Cell (2008) 19:2857-69. doi: 10.1091/mbc.e07-10-1094

57. De Franceschi N, Hamidi H, Alanko J, Sahgal P, Ivaska J. Integrin traffic-the update. J Cell Sci. (2015) 128:839-52. doi: 10.1242/jcs.161653

58. Den Hartog G, Van Altena C, Savelkoul HF, Van Neerven RJ. The mucosal factors retinoic acid and TGF-beta1 induce phenotypically and functionally distinct dendritic cell types. Int Arch Allergy Immunol. (2013) 162:225-36. doi: 10.1159/000353243

59. Farache J, Koren I, Milo I, Gurevich I, Kim KW, Zigmond E, et al. Luminal bacteria recruit $\mathrm{CD} 103+$ dendritic cells into the intestinal epithelium to sample bacterial antigens for presentation. Immunity (2013) 38:581-95. doi: 10.1016/j.immuni.2013.01.009

60. Taraszka KS, Higgins JM, Tan K, Mandelbrot DA, Wang JH, Brenner MB. Molecular basis for leukocyte integrin alpha(E)beta(7) adhesion to epithelial (E)-cadherin. J Exp Med. (2000) 191:1555-67. doi: 10.1084/jem.191.9.1555

61. Tang A, Amagai M, Granger LG, Stanley JR, Udey MC. Adhesion of epidermal Langerhans cells to keratinocytes mediated by E-cadherin. Nature (1993) 361:82-5. doi: 10.1038/361082a0

62. Hubert P, Caberg JH, Gilles C, Bousarghin L, Franzen-Detrooz E, Boniver $\mathrm{J}$, et al. E-cadherin-dependent adhesion of dendritic and Langerhans cells 
to keratinocytes is defective in cervical human papillomavirus-associated (pre)neoplastic lesions. J Pathol. (2005) 206:346-55. doi: 10.1002/path.1771

63. Lacaz-Vieira F. Calcium site specificity. Early Ca2+-related tight junction events. J Gen Physiol. (1997) 110:727-40. doi: 10.1085/jgp.110.6.727

64. Nagafuchi A, Takeichi M. Cell binding function of E-cadherin is regulated by the cytoplasmic domain. EMBO J. (1988) 7:3679-84. doi: 10.1002/j.1460-2075.1988.tb03249.x

65. Ni H, Li A, Simonsen N, Wilkins JA. Integrin activation by dithiothreitol or $\mathrm{Mn} 2+$ induces a ligand-occupied conformation and exposure of a novel NH2-terminal regulatory site on the betal integrin chain. J Biol Chem. (1998) 273:7981-7. doi: 10.1074/jbc.273.14.7981

66. Ito $M$, Maruyama $\mathrm{T}$, Saito $\mathrm{N}$, Koganei S, Yamamoto $\mathrm{K}$, Matsumoto $\mathrm{N}$. Killer cell lectin-like receptor G1 binds three members of the classical cadherin family to inhibit NK cell cytotoxicity. J Exp Med. (2006) 203:289-95. doi: 10.1084/jem.20051986

67. Banh C, Fugere C, Brossay L. Immunoregulatory functions of KLRG1 cadherin interactions are dependent on forward and reverse signaling. Blood (2009) 114:5299-306. doi: 10.1182/blood-2009-06-228353

68. Cavarelli M, Foglieni C, Rescigno M, Scarlatti G. R5 HIV-1 envelope attracts dendritic cells to cross the human intestinal epithelium and sample luminal virions via engagement of the CCR5. EMBO Mol Med. (2013) 5:776-94. doi: $10.1002 / \mathrm{emmm} .201202232$

69. Schittenhelm L, Hilkens CM, Morrison VL. $\beta_{2}$ integrins as regulators of dendritic cell, monocyte, and macrophage function. Front Immunol. (2017) 8:1866. doi: 10.3389/fimmu.2017.01866

70. Crowe SE, Alvarez L, Dytoc M, Hunt RH, Muller M, Sherman P, et al. Expression of interleukin 8 and CD54 by human gastric epithelium after Helicobacter pylori infection in vitro. Gastroenterology (1995) 108:65-74. doi: 10.1016/0016-5085(95)90009-8
71. Mane V, Muro S. Biodistribution and endocytosis of ICAM-1targeting antibodies versus nanocarriers in the gastrointestinal tract in mice. Int J Nanomed. (2012) 7:4223-37. doi: 10.2147/IJN.S 34105

72. Shen B, Delaney MK, Du X. Inside-out, outside-in, and insideoutside-in: $G$ protein signaling in integrin-mediated cell adhesion, spreading, and retraction. Curr Opin Cell Biol. (2012) 24:600-6. doi: 10.1016/j.ceb.2012.08.011

73. Le Floc'h A, Jalil A, Franciszkiewicz K, Validire P, Vergnon I, MamiChouaib F. Minimal engagement of CD103 on cytotoxic T lymphocytes with an E-cadherin-Fc molecule triggers lytic granule polarization via a phospholipase Cgamma-dependent pathway. Cancer Res. (2011) 71:328-38. doi: 10.1158/0008-5472.CAN-10-2457

74. Russell GJ, Parker CM, Cepek KL, Mandelbrot DA, Sood A, Mizoguchi E, et al. Distinct structural and functional epitopes of the alpha E beta 7 integrin. Eur J Immunol. (1994) 24:2832-41. doi: 10.1002/eji.18302 41138

Conflict of Interest Statement: The authors declare that the research was conducted in the absence of any commercial or financial relationships that could be construed as a potential conflict of interest.

Copyright (C) 2018 Swain, Roe, Sebrell, Sidar, Dankoff, VanAusdol, Smythies, Smith and Bimczok. This is an open-access article distributed under the terms of the Creative Commons Attribution License (CC BY). The use, distribution or reproduction in other forums is permitted, provided the original author(s) and the copyright owner(s) are credited and that the original publication in this journal is cited, in accordance with accepted academic practice. No use, distribution or reproduction is permitted which does not comply with these terms. 